\title{
A soil moisture and temperature network for SMOS validation in Western Denmark
}

\author{
S. Bircher ${ }^{1}$, N. Skou ${ }^{2}$, K. H. Jensen ${ }^{1}$, J. P. Walker ${ }^{3}$, and L. Rasmussen ${ }^{4}$ \\ ${ }^{1}$ University of Copenhagen, Department of Geography and Geology, Copenhagen, Denmark \\ ${ }^{2}$ Technical University of Denmark, DTU Space, Kgs. Lyngby, Denmark \\ ${ }^{3}$ Monash University, Department of Civil Engineering, Monash University Victoria, Australia \\ ${ }^{4}$ Aarhus University, Department of Earth Sciences, Aarhus, Denmark
}

Correspondence to: S. Bircher (simone.bircher@geo.ku.dk)

Received: 30 October 2011 - Published in Hydrol. Earth Syst. Sci. Discuss.: 14 November 2011

Revised: 12 April 2012 - Accepted: 18 April 2012 - Published: 16 May 2012

\begin{abstract}
The Soil Moisture and Ocean Salinity Mission (SMOS) acquires surface soil moisture data of global coverage every three days. Product validation for a range of climate and environmental conditions across continents is a crucial step. For this purpose, a soil moisture and soil temperature sensor network was established in the Skjern River Catchment, Denmark. The objectives of this article are to describe a method to implement a network suited for SMOS validation, and to present sample data collected by the network to verify the approach. The design phase included (1) selection of a single SMOS pixel $(44 \times 44 \mathrm{~km})$, which is representative of the land surface conditions of the catchment and with minimal impact from open water (2) arrangement of three network clusters along the precipitation gradient, and (3) distribution of the stations according to respective fractions of classes representing the prevailing environmental conditions. Overall, measured moisture and temperature patterns could be related to the respective land cover and soil conditions. Texture-dependency of the $0-5 \mathrm{~cm}$ soil moisture measurements was demonstrated. Regional differences in $0-5 \mathrm{~cm}$ soil moisture, temperature and precipitation between the north-east and south-west were found to be small. A first comparison between the $0-5 \mathrm{~cm}$ network averages and the SMOS soil moisture (level 2) product is in range with worldwide validation results, showing comparable trends for SMOS retrieved soil moisture $\left(R^{2}\right.$ of 0.49$)$ as well as initial soil moisture and temperature from ECMWF used in the retrieval algorithm $\left(R^{2}\right.$ of 0.67 and 0.97 , respectively). While retrieved/initial SMOS soil moisture indicate significant under-/overestimation of the network data (biases
\end{abstract}

of $-0.092 / 0.057 \mathrm{~m}^{3} \mathrm{~m}^{-3}$ ), the initial temperature is in good agreement (bias of $-0.2^{\circ} \mathrm{C}$ ). Based on these findings, the network performs according to expectations and proves to be well-suited for its purpose. The discrepancies between network and SMOS soil moisture will be subject of subsequent studies.

\section{Introduction}

The assessment of water resources is vital under changing climate and land use, especially when coupled with a steadily increasing population (e.g. FAO-AQUASTAT, 2003). Climate and hydrological models constitute important tools for such investigations, but their reliability is constrained due to uncertainty in important input parameters. One of the key variables is soil moisture, as it significantly impacts water and energy exchanges at the land surface-atmosphere interface, and it represents the main source of water for agriculture and natural vegetation. However, soil moisture is highly variable in space and time and across scales, as a result of spatial heterogeneity in soil and land cover properties, topography and climatic drivers (Famiglietti et al., 1998; Mohanty et al., 2000; Western et al., 2002) rendering it very difficult to assess. Thus, global long-term soil moisture observations of good quality are urgently needed.

Space-borne sensors are the only means to provide such measurements. Starting in the seventies, different approaches have been developed to retrieve surface soil moisture from space-borne acquisitions in the microwave frequency 
domain, taking advantage of the large contrast of the dielectric constant between solid soil particles and water. Several passive and active sensors have been used, e.g. SMMR and SSM/I (Owe et al., 2001), AMSR-E (Owe et al., 2001; Njoku et al., 2003), WindSat (Li et al., 2010), as well as ERSASCAT and METOP-ASCAT (Wagner et al., 1999; Naeimi et al., 2009). These systems are operating at frequencies above 5-20 GHz where the sensitivity to vegetation growth, atmosphere and roughness effects starts increasing drastically. Despite this fact, they constitute a meaningful time series. Launched in November 2009, the first space-borne passive L-band microwave $(1.4 \mathrm{GHz})$ radiometer operating at the preferred frequency for soil moisture retrieval is the Soil Moisture and Ocean Salinity (SMOS) mission (Kerr et al., 2001, 2010) - a multi-angle, fully polarimetric system on board the satellite offers unprecedented possibilities for retrieving surface soil moisture data $(\sim 0-5 \mathrm{~cm}$ depth) of global coverage every three days at a spatial resolution of $\sim 44 \mathrm{~km}$. However, like for the previous sensors, SMOS data quality is potentially affected by Radio Frequency Interferences (RFI), unresolved image reconstruction issues, as well as errors in both the retrieval algorithm and related input. Thus, it is important that the SMOS algorithm and its associated products be validated by independent in situ measurements across a range of climatic regions.

Generally, such comparisons are complicated by scalemismatch between the large satellite footprints and the point measurements on the ground (Cosh et al., 2004), entailing the necessity of a high number of distributed observations of the latter to accurately represent the satellite scale. Continuous soil moisture networks have recently evolved across all continents and constitute a core activity in the validation of SMOS data: e.g. USA (Bosch et al., 2006; Schaefer et al., 2007; Jackson et al., 2010); Canada (Champagne et al., 2010); Australia (Walker et al., 2001; Merlin et al., 2008); Africa (de Rosnay et al., 2009); Europe - Spain (Martinez-Fernandez and Ceballos, 2003, 2005), France (Calvet et al., 2007; Albergel et al., 2008), Germany (Krauss et al., 2010; Bogena et al., 2010). Many of them can be found in the International Soil Moisture Network Database (ISMN, Dorigo et al., 2011). These networks often face constraints with respect to their density or spatial extent (Cosh et al., 2004). Various upscaling techniques have evolved to derive spatial patterns at large scales, e.g. interpolation (Bardossy and Lehmann, 1998), time/rank stability (Vachaud et al., 1985), statistical transformation (Reichle and Koster, 2004; De Lannoy et al., 2007), and land surface modeling (Crow et al., 2005). However, these methods are sometimes themselves vulnerable to coarse spacing or limited extent of in situ data, often requiring costly long-term pre-studies. As this is not possible in most cases, methods to a priori design networks in a spatially representative manner would be beneficial. Friesen et al. (2008) presented an approach of area-weighted sampling by means of landscape units (hydrotopes) with internally more consistent hydrologic behavior, whereby variance and bias in the largescale in situ soil moisture average can be reduced. The method was successfully applied in two short-term campaigns in West Africa. However, it is both region-dependent and quite complex.

Several studies have focused on the number of samples required to estimate the satellite footprint-scale mean. It was noted that soil moisture variability increases with the spatial extent of a footprint, implying an increase in the necessary number of measurements (Western and Bloeschl, 1999; Famiglietti et al., 1999, 2008). Brocca et al. (2007) found that a minimum of 15 to 35 point samples were required for terrain in central Italy of negligible to significant topography and an extent of around $0.005-0.01 \mathrm{~km}^{2}$. An extended study for an area of approximately $60 \mathrm{~km}^{2}$ by Brocca et al. (2010) revealed a maximum number of required samples of around 35 up to a soil moisture content of $0.3 \mathrm{~m}^{3} \mathrm{~m}^{-3}$ (please note that in the following this dimensionless unit will be omitted). Applying a temporal stability analysis this number could be reduced to 10. In the central USA Famiglietti et al. (2008) found a maximum of 30 samples to be required at the $50 \times 50 \mathrm{~km}^{2}$ scale assuming independent and spatially uncorrelated data.

A SMOS validation site has been established in the Skjern River Catchment in Western Denmark (Bircher et al., 2012a). In the framework of the Hydrological Observatory (HOBE, www.hobe.dk, Jensen and Illangasekare, 2011), a soil moisture and temperature network was installed in fall 2009 within one SMOS pixel $(44 \times 44 \mathrm{~km})$ covering large parts of the catchment. Due to temporal constraints a sufficiently long pre-study with a dense enough set-up for the determination of time stable sites was impossible. To compensate for this shortcoming a number of 30 stations was chosen which is relatively high compared to several other networks (see for example in the ISMN database, www.ipf.tuwien.ac.at/insitu/), as well as close to the upper end of the proposed range in the above-mentioned studies. Furthermore, the selection of the individual network stations was based on precedent careful analysis of soil moisture influencing variables and the SMOS retrieval concept including its data arrangement over the area in order to a priori enhance the representativeness of the setup. In this context, the objectives of this article are (1) to describe a simple method for the design and implementation of a soil moisture network suited for SMOS validation, and (2) to present the network data set and some analysis including a first comparison with SMOS data to verify the feasibility of our approach, as well as the reliability of the collected data. The design is split into the selection of (1) an appropriate SMOS pixel, (2) three network clusters within the pixel, and (3) suitable network locations within the clusters. In step 3, a method similar to Friesen et al. (2008) is applied with distribution of the individual stations according to the respective fractions of the prevailing environmental conditions. Friesen et al. (2008) defined the main landscape units a priori, which introduces a risk to exclude important features from 
the start. In contrast, in our much simpler method all environmental information is going into the analysis unchanged, whereupon the most important landscape units of the region are detected. Following this approach, we are proposing a method to obtain a large-scale in situ soil moisture average suitable for comparison with SMOS data.

\section{Study area}

The Skjern River Catchment is situated in Western Denmark and covers an area of approximately $2500 \mathrm{~km}^{2}$ (Fig. 1). The climate in the region is temperate-maritime with winter and summer mean temperatures of around 2 and $16^{\circ} \mathrm{C}$, respectively, and an approximate annual precipitation between 800 to $900 \mathrm{~mm}$. The eastern margin of the catchment is situated at the rim of the ice sheet during the latest glacial advance with mainly loamy soils on undulating calcareous tills. The remaining part comprises the primal fluvioglacial outwash plain consisting of low-relief sandy soils and sediments, while poorly drained basins have been filled with organic material (Greve et al., 2007).

The predominant naturally occurring soil type is podsol with a bleached quartz-rich eluviation zone (topsoil) and an illuvation zone (subsoil) usually composed of a hardpan with a black organic-rich band and a subjacent orange-brown layer of sesquioxides with often distinct mottling (Scheffer and Schachtschabel, 2002). While water drains quickly through the sandy topsoil, this very firm hardpan is almost water tight causing ponding of water at its surface. When fertilized, limed and irrigated high-yield cultivation is possible; this is the case in the major part of the Skjern River Catchment. Intermixed are patches of natural vegetation, i.e. grassland, heath and spruce plantations with pronounced raw humus layers (typically found on podsols). The area is sparsely populated with scattered farms and villages.

Within the catchment four study sites were chosen for the HOBE project (Jensen and Illangasekare, 2011, Fig. 1) to assess a wealth of hydrological parameters. The catchment is well-covered with climate and weather stations operated by the Danish Meteorological Institute (DMI). The daily precipitation (24-h sums) presented in this article are extracted from the DMI $10 \times 10 \mathrm{~km}$ precipitation grid nodes (Scharling, 1999) contained within the SMOS pixel (Fig. 1).

\section{Data}

\subsection{Network data}

A total of 30 Decagon ECH2O data loggers (Decagon Devices, 2002) were installed, each holding three ECH2O 5TE capacitance sensors measuring soil moisture, temperature,

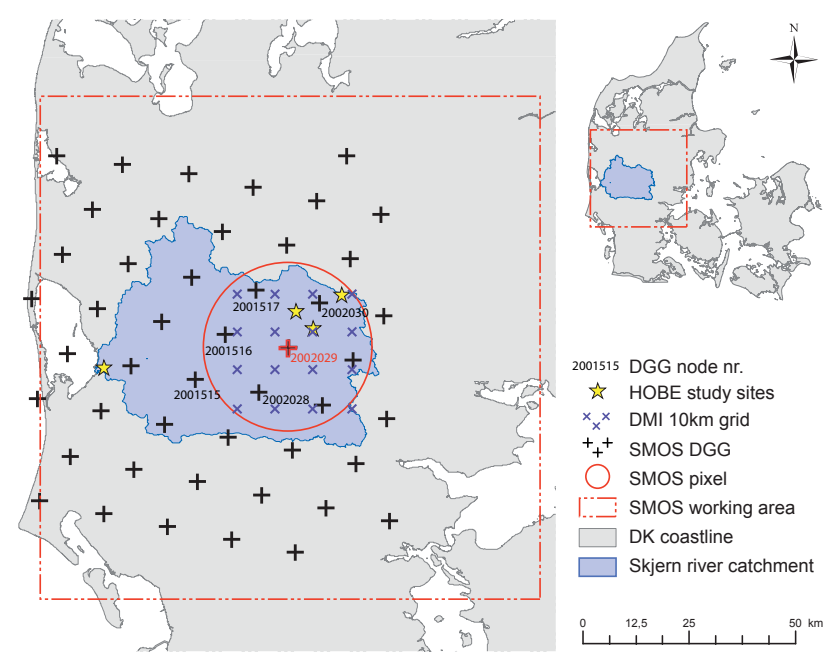

Fig. 1. Skjern River Catchment in Western Denmark, HOBE study sites, SMOS Discrete Global Grid (DGG) nodes including numbers of eligible nodes, selected SMOS pixel and corresponding working area around grid node 2002029 , and DMI $10 \mathrm{~km}$ precipitation grid within SMOS pixel.

and electrical conductivity (Decagon Devices, 2008) ${ }^{1}$. The 5TE sensors were considered to be a cost-effective solution for large network applications. They are well-suited for measurements in the near-surface layer and provide integrated measurements over approximately $5-6 \mathrm{~cm}$ when installed horizontally ( 0.31 measurement volume). According to the manufacturer, accuracies in mineral soils are \pm 0.03 and $\pm 1{ }^{\circ} \mathrm{C}$ for water content and temperature, respectively. Using the empirical calibration equation of Topp et al. (1980) volumetric water content is derived from dielectric permittivity, which in turn results from a 5 point dielectric calibration.

The TE sensors (predecessors of 5TE) were excessively tested in soils ranging from $3-100 \%$ sand $/ 0-53 \%$ clay and salt-water solutions of electrical conductivities from 1 to $12 \mathrm{dS} \mathrm{m}^{-1}$ by Kizito et al. (2008). They found little probe to probe variability and sufficiently small sensitivity to temperature and electrical conductivity so that one single calibration curve was applicable for all studied conditions. Similarly, for the 5TE sensor type Vasquez and Thomsen (2010) found the Topp equation to be accurate within \pm 0.02 in the $0-0.5 \mathrm{~m}$ depth range at the HOBE agriculture site Voulund (where one network station was placed).

Famiglietti et al. (2008) pointed out, that though sitespecific calibration is ideal it is impractical for studies with large sensor numbers distributed over a considerable spatial extent. In their $50 \times 50 \mathrm{~km}^{2}$-scale survey they applied a generalized calibration method with an accuracy of \pm 0.03 to the entire set of probes, and likewise, this was done by Brocca et al. (2010).

\footnotetext{
${ }^{1}$ Mention of manufacturers is for the convenience of the reader only and implies no endorsement on the part of the authors.
} 
Given the above findings, the Decagon 5TE calibration equation (Topp et al., 1980) has been applied to the network. The given accuracy has been confirmed by some independent testing (addressed in Sects. 4.3 and 5.1).

\subsection{SMOS data}

The SMOS measurement and soil moisture retrieval concept is complex and will be described to the extent required for understanding the presented work. For further information reference is made to Kerr et al. $(2001,2010,2011)$. The SMOS data presented in this article is the one reprocessed by the Centre d'Etudes Spatiales de la BIOsphère (CESBIO) using the state-of-the-art L2 prototype algorithm (V4.00) at the time this work was conducted.

The radiation collected by the SMOS radiometer is emitted from the area illuminated by the antenna directional gain pattern (working area, $\sim 123 \times 123 \mathrm{~km}^{2}$. Measurements are made in full polarization and incidence angles ranging from around 0 to $60^{\circ}$ as the satellite passes over the terrain. The working area is characterized by a weighting function so that approximately $80 \%$ of the acquired energy comes from an area of about $44 \mathrm{~km}$ in diameter around the node (SMOS pixel).

To derive the level 2 (L2) soil moisture product, brightness temperatures $T_{\mathrm{B}}$ as acquired by SMOS (proportional to the measured radiation) are modeled for both polarizations at each incidence angle by means of the L-band Microwave Emission of the Biosphere (L-MEB) forward model (Wigneron et al., 2007). An initial soil moisture guess and auxiliary parameters (e.g. soil properties, land cover information, leaf area index, topography, temperature and other climate parameters) are required as input. Modeled and measured $T_{\mathrm{B}} \mathrm{S}$ are compared, and by minimizing a cost function, soil moisture is iteratively retrieved for each node of a fixed earth surface grid (Discrete Global Grid DGG) with uniform spacing $(\sim 15 \mathrm{~km})$. Figure 1 illustrates the locations of the DGG nodes in the Skjern River Catchment, including the working area and corresponding SMOS pixel around one grid node. The soil moisture and temperature initial guesses presented in Sect. 5.3.3 are contained in the L2 product. They both originate from the model output of the European Centre for Medium-range Weather Forecasting (ECMWF) operational forecast system, available at 3-hourly intervals based on the 00:00 and 12:00 Coordinated Universal Time (UTC) data, and spatially and temporally aggregated over the working area.

L-MEB is based on the relationship between $T_{\mathrm{B}}$, physical temperature and the land surface emissivity/reflectivity, which in turn is related to the soil's dielectric constant after segregating atmosphere, vegetation and surface roughness contributions using the multi-angular and dual-polarized information. Taking advantage of the large contrast between the dielectric properties of water and solid soil particles at L-band, soil moisture is linked to the dielectric constant via the Dobson dielectric mixing model (Dobson et al., 1985; Peplinski et al., 1995).

L-MEB is built for uniform scenes with certain model characteristics and calibration parameters. However, the above-mentioned auxiliary input parameters are mostly heterogeneous at significantly smaller spatial scales than SMOS pixels. To account for this, the retrieval algorithm aggregates the estimated contributions from several elementary land cover classes derived from ECOCLIMAP (Masson et al., 2003). This data set is previously grouped into eight generic classes (bare soil and low vegetation covers, forests, open water, barren rocks, frozen soils, snow covered areas, ice, and urban areas) and interpolated on a $4 \times 4 \mathrm{~km}^{2}$ reference grid (Discrete Flexible Fine Grid, DFFG) centered on each DGG node. Within the working area radiometric fractions of each generic land cover class are estimated by means of the antenna weighting function. For the class with the highest radiometric fraction soil moisture is retrieved using the respective elementary model as well as auxiliary input (provided at the DFFG scale), while the other classes contribute with fixed default values based on the auxiliary information.

\section{Methodology}

\subsection{Network design}

\subsubsection{Selection of SMOS pixel}

Installing the network in the area of major SMOS signal contribution around one DGG node (for which soil moisture is retrieved) offers the advantage that no error-prone interpolation of SMOS data is necessary before comparison with the ground data. Two criteria were taken into account when selecting a SMOS DGG node and the surrounding pixel to be validated: (1) the spatial overlap between the SMOS pixel and the Skjern River Catchment including the HOBE study sites should be maximized, and (2) the open water fraction within the working area affiliated with the SMOS pixel should be minimized. The latter is of importance as water bodies exhibit very different brightness temperatures than those observed over land, which can significantly impact the soil moisture retrieval result. Eligible SMOS nodes are shown in Fig. 1. Corresponding radiometric open water fractions contained in the respective working areas of DGG nodes 2001 515, 2001 516, 2001 517, 2002028,2002029 and 2002030 are $1.85,0.51,0.29,0.25,0.24$ and $0.56 \%$, respectively. While all these amounts are very small, the SMOS pixel around node 2002029 provides the best coverage of the catchment including the HOBE study sites and was thus chosen for validation.

\subsubsection{Selection of network clusters}

Despite a good road network, driving around in a $44 \times 44 \mathrm{~km}^{2}$ area is very time consuming. Thus, to minimize 
maintenance costs the network was designed by dividing the 30 monitoring stations into three clusters with diameters of up to $\sim 10 \mathrm{~km}$ (Fig. 2). One cluster was centered on the SMOS grid node as this represents the area from which the highest radiation fractions originate. A second cluster was allocated to the north-east of the SMOS pixel, around the HOBE agriculture site Voulund with one network station at the study site to render the data connectable to other geophysical measurements. For the same reason one network station was assigned to the HOBE forest site Gludsted, situated some kilometers east of this cluster. The third cluster was placed in the south-west to account for the spatial gradient observed in the mean annual precipitation for the period 1990 to $2005(10 \times 10 \mathrm{~km}$ grid, Scharling, 1999) from south-west $\left(\sim 900 \mathrm{~mm} \mathrm{yr}^{-1}\right)$ to north-east $\left(\sim 800 \mathrm{~mm} \mathrm{yr}^{-1}\right)$. Furthermore, two stations were placed in the south-east to account for the more loamy soils in the eastern part of the SMOS pixel (see Sect. 2).

\subsubsection{Selection of theoretical station locations}

For positioning the station locations within these cluster areas, a Geographic Information System (GIS) analysis was performed, thus determining the most representative combinations of environmental conditions (topography, land cover and soil type) within the SMOS pixel. Elevations span from $0 \mathrm{~m}$ at the western coastline to around $180 \mathrm{~m}$ a.s.l. in the eastern part of the Skjern River Catchment with 99.8 and $98.5 \%$ of the derived slopes $<5^{\circ}$ for the SMOS pixel and working area of DGG 2002029 , respectively (90 m digital elevation model of the Shuttle Radar Topographic Mission, Jarvis et al., 2008). No SMOS topography flags are set for node 2002029 . Consequently, topographical effects were neglected in the successive analysis.

Table 1 summarizes soil types with respective grain size distribution and organic matter content of the $0-20 \mathrm{~cm}$ topsoil layer (250 m Danish topsoil grid, Greve et al., 2007). Accordingly, Table 2 shows the subsoil composition below $30 \mathrm{~cm}$ depth (clay versus sand) with corresponding clay contents based on a map from Bornebusch and Milthers (1935), Smed (1979), Schou (1949), and Milthers (1939). In both tables respective soil type fractions contained in the SMOS pixel and working area around node 2002029 are given. While the pixel comprises almost $80 \%$ coarse sand in the topsoil and $89 \%$ sand in the subsoil, these percentages are lowered to $46 \%$ and $70 \%$ for the entire working area due to a fractional shift towards more loamy soils concurring with the position of the latest glacial ice margin.

Table 3 illustrates land cover fractions (CORINE Land Cover $2000100 \mathrm{~m}$ grid, level 2, EEA, 2005; Bossard et al., 2000 ) within the SMOS pixel and working area around node 2002029 , respectively. They are comparable for the two spatial scales with agriculture taking the major parts, followed by forest (mainly coniferous) and shrub/grassland (heath). In agreement with the corresponding SMOS radiometric

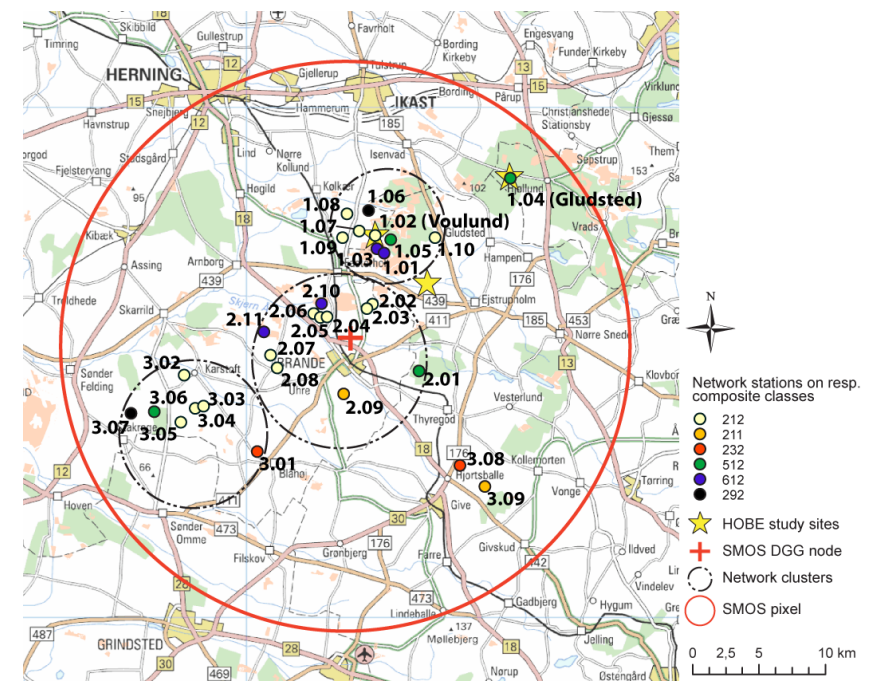

Fig. 2. Overview of the 30 soil moisture network stations installed in the Skjern River Catchment, Western Denmark, within three clusters in the selected SMOS pixel around Discrete Global Grid node 2002029.

fractions, water bodies only exhibit marginal parts. Land cover exerts strong influence on the SMOS soil moisture algorithm through both choice of the retrieval model and high non-linearity of vegetation parameters. Thus, it is of importance that the area for which the network delivers soil moisture data is representative for the entire working area in terms of land cover, while this is less relevant in case of soil types.

To find the most representative combinations of topsoil, subsoil, and land cover types within the SMOS pixel, the individual data sets were re-sampled and snapped to the land cover $100 \mathrm{~m}$-grid (Fig. 3a-c). Using the nearest neighbor resampling technique merely changed the cell size while all categorical information was conserved. The land cover, topand subsoil data sets were reclassified to values of $100 \mathrm{~s}, 10 \mathrm{~s}$ and 1 digits ("reclass values" in Tables 1-3), and summed up to one grid containing all possible combinations of the original layers (referred to "composite class map" hereafter, Fig. 3d). Figure 4 displays the composite class fractions revealing five classes $(212,232,412,512$ and 612) with individual shares of $>5 \%$. Together they constitute approximately $75 \%$ of the SMOS pixel and all have a tendency towards very sandy soils. Including the most frequent classes with high fraction of organic material (humus) in the topsoil (292) and clay in the subsoil (211), $\sim 82 \%$ of the prevailing environmental conditions in the validation area are incorporated, which is regarded as a good overall representation. Table 4 gives an overview of these selected composite classes including a description and respective class fractions. As CORINE land cover class 400 (heterogeneous agriculture) contains all prevailing land cover types (arable land intermixed with forest and shrub/grassland, Bossard et al., 2000), the composite class 412 was repartitioned equally to 
Table 1. Topsoil information (0-20 cm depth): soil type, class numbers used in the sum-up to composite classes, textural fractions [\%] of clay $(<2 \mu \mathrm{m})$, silt $(2-20 \mu \mathrm{m})$, fine sand $(20-200 \mu \mathrm{m})$ and total sand $(20-2000 \mu \mathrm{m})$, organic matter content (humus, 58.7\% C) [\%], and respective fractions [\%] of soil type contained in the SMOS pixel and working area around Discrete Global Grid node 2002029.

\begin{tabular}{|c|c|c|c|c|c|c|c|c|}
\hline Soil type & $\begin{array}{r}\text { Recl. } \\
\text { val. }\end{array}$ & Clay & Silt & $\begin{array}{l}\text { Fine } \\
\text { sand }\end{array}$ & $\begin{array}{l}\text { Total } \\
\text { sand }\end{array}$ & Humus & $\begin{array}{r}\text { SMOS } \\
\text { pixel }\end{array}$ & $\begin{array}{r}\text { Working } \\
\text { area }\end{array}$ \\
\hline Coarse sand & 10 & $0-5$ & $0-20$ & $0-50$ & $75-100$ & $<10$ & 79 & 46 \\
\hline Fine sand & 20 & & & $50-100$ & & & 0 & 3 \\
\hline Coarse loamy sand & 30 & $5-10$ & $0-25$ & $0-40$ & $65-95$ & & 13 & 17 \\
\hline Fine loamy sand & 40 & & & $40-95$ & & & 2 & 13 \\
\hline Coarse sandy loam & 50 & $10-15$ & $0-30$ & $0-40$ & $55-90$ & & 0 & 4 \\
\hline Fine sandy loam & 60 & & & $40-90$ & & & 0 & 9 \\
\hline Clay loam & 70 & $15-25$ & $0-35$ & & $40-85$ & & 0 & 2 \\
\hline Organic material/humus & 90 & & & & & $>10$ & 6 & 6 \\
\hline
\end{tabular}
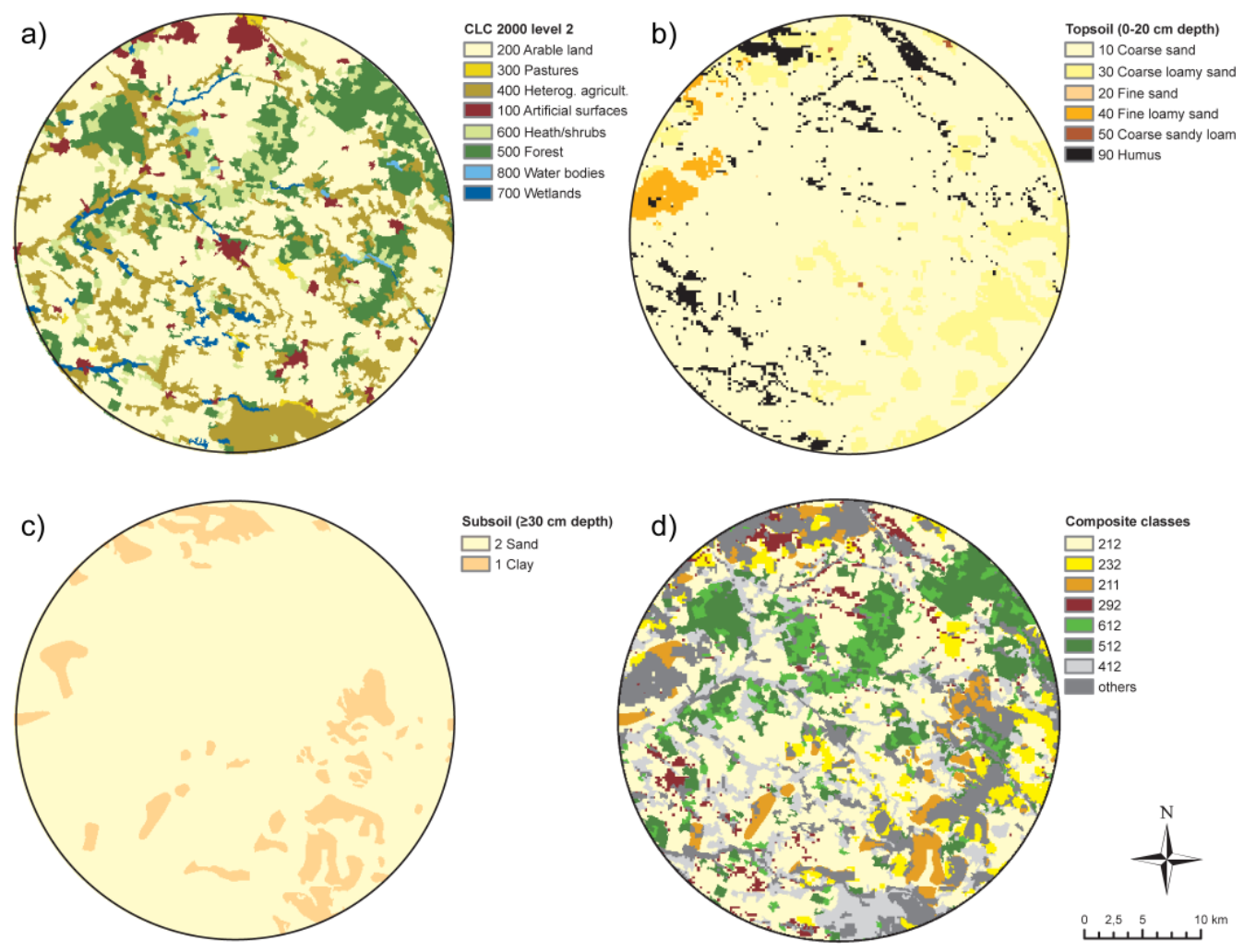

Fig. 3. Land cover type (a), topsoil types (b), subsoil types (c) and composite classes, combining land cover type, topsoil and subsoil types (d) within the selected SMOS pixel around SMOS Discrete Global Grid node 2002029.

the classes 212 and 612 (same soil type). The 30 network stations were then distributed among these six classes according to their respective fractions. Table 4 also gives a descriptive code for each composite class $(\mathrm{A}=$ agriculture, $\mathrm{F}=$ forest, $\mathrm{H}=$ heath, $\mathrm{S}=$ sand, $\mathrm{L}=$ loamy sand, $\mathrm{O}=$ organic material/humus, so that for example ASC stands for agriculture as land cover, sand in topsoil and clay in subsoil). In the following, this code is used together with the class number to augment comprehensibility.
Plant structure has an influence on vegetation parameters in the SMOS soil moisture algorithm. Thus, the predominant crop types were estimated based on the field plan 2005 (FVM, 2005) as well as areal cultivation statistics 2006-2008 (Danmarks Statistik and Service, 2009, Table 5) for Central Western Denmark. The 22 agricultural network stations were allocated to fields with the three most frequent crops barley, grass and winter wheat, and additionally to maize and potatoes (differing plant structure) according to respective fractions. 
Table 2. Subsoil composition ( $>30 \mathrm{~cm}$ depth): soil type, class numbers used in the sum-up to composite classes, clay fractions $(<2 \mu \mathrm{m})$ [\%] and respective fractions [\%] contained in the SMOS pixel and working area around Discrete Global Grid node 2002029.

\begin{tabular}{lrrrr}
\hline Soil type & Recl. val. & Clay & SMOS pixel & Working area \\
\hline Clay & 1 & $>15$ & 11 & 30 \\
Sand & 2 & $<10($ mostly $<5)$ & 89 & 70 \\
\hline
\end{tabular}

\subsection{Network implementation}

\subsubsection{Field inspection/final decision on station locations}

Provisionally, the stations were distributed among the three network clusters using the composite class map (Fig. 3d). Final decisions on the locations were taken after field inspection. Due to the extensive road network, access did not constrain the choice.

For forest and heath (composite classes 512/FSS and $612 / H S S$ ), no reallocation of the pre-selected points was necessary, as theoretically estimated land cover and soil types were in good agreement with actual conditions. Three stations were placed under scotch heather, one under natural grass, and four under spruce plantations characterized by pronounced row structure, scarce understory and moss carpets. All these locations exhibit distinct organic surface layers.

The estimated occurrence of agricultural areas and crop types was also encountered in reality, and in case of the composite class 212/ASS the expected very sandy topand subsoils were clearly perceived at the preselected locations. However, the distinction between classes 212/ASS and 292/AOS (sand and humus in the topsoil, respectively) was almost impossible, as the upper soil layer exhibited a very dark color at all investigated locations, due to intermixed organic matter as a result of agricultural practices. Likewise, for locations where classes with higher clay fractions were indicated on the composite class map (i.e. class 211/ASC with clay in the subsoil or class 232/ALS with loamy sand in the top soil) we could solely notice that soils clearly exhibited greater clay contents than the sandy classes. In situ discrimination between class 211/ASC and 232/ALS turned out to be difficult. Furthermore, at locations where an increased clay fraction was noticed, it persisted usually throughout the entire depth profile. As classes 211/ASC, 232/ALS and 292/AOS only account for a small fraction of the entire SMOS pixel $(\sim 13 \%)$, these inaccuracies were accepted when placing the corresponding stations. We resigned the labor-intensive determination of texture and organic amounts for the localization of spots with the exact soil properties inherent in the respective composite classes.

The estimated number of stations per crop type could be maintained, even though some adjustments had to be made between the composite classes (Table 5). This was
Table 3. Land cover information: land cover type, class numbers used in the sum-up to composite classes, and respective fractions [\%] contained in the SMOS pixel and working area around Discrete Global Grid node 2002029.

\begin{tabular}{lrrr}
\hline Land cover descr. & $\begin{array}{r}\text { Recl. } \\
\text { val. }\end{array}$ & $\begin{array}{r}\text { SMOS } \\
\text { pixel }\end{array}$ & $\begin{array}{r}\text { Working } \\
\text { area }\end{array}$ \\
\hline $\begin{array}{l}\text { Artificial surfaces } \\
\text { Urban }\end{array}$ & 100 & 2 & 3 \\
Industry, transport & & 1 & 1 \\
Artificial vegetation & & 0 & 1 \\
Agricultural areas & & & \\
Arable land & 200 & 57 & 63 \\
Pastures & 300 & 1 & 1 \\
Heterogeneous agriculture & 400 & 16 & 13 \\
Forest and semi natural areas & & & \\
Coniferous forests & 500 & 14 & 11 \\
Shrub and grassland & 600 & 7 & 5 \\
Wetlands & & & \\
Inland wetlands & 700 & 2 & 1 \\
Water bodies & & & \\
Inland waters & 800 & 0 & 1 \\
\hline
\end{tabular}

accepted since crop rotations change throughout the years. An overview of the final network locations is given in Fig. 2 and Table 6.

\subsubsection{Installation}

Sensor installation took place in fall 2009. At each station, three 5TE sensors were placed at respective depths of 2.5, 22.5 and $52.5 \mathrm{~cm}$ (corresponding to measurement intervals of $\sim 0-5,20-25$ and $50-55 \mathrm{~cm}$ ) from the soil surface after removal of the litter/organic layer (Fig. 5). The sensors were horizontally inserted with the blade in the vertical position to avoid ponding.

While for SMOS validation the $0-5 \mathrm{~cm}$ data is of most importance, the profile measurements suit the needs of hydrological modeling activities in the HOBE project, possibly in combination with assimilated SMOS data. With respect to heath and forest stations, one 5TE sensor was additionally installed in the organic layer in summer 2010. This is crucial as the signal measured by SMOS over these areas most probably originates exclusively from this moist layer (Bircher et al., 2010).

Sensor readings are logged in $30 \mathrm{~min}$ intervals. Stations placed in crops have to be temporarily removed during cultivation practices (seed/plantation and harvest) - twice for summer crops (spring and fall) and once for winter crops (late summer). After these field preparations the soil structure may be changed. Thus, even if leading to some measurement gaps, we believe that sampling soil corresponding to the actual encountered conditions is of higher importance in order to acquire representative data, especially, given that $80 \%$ of the studied SMOS pixel is covered with agricultural land. 


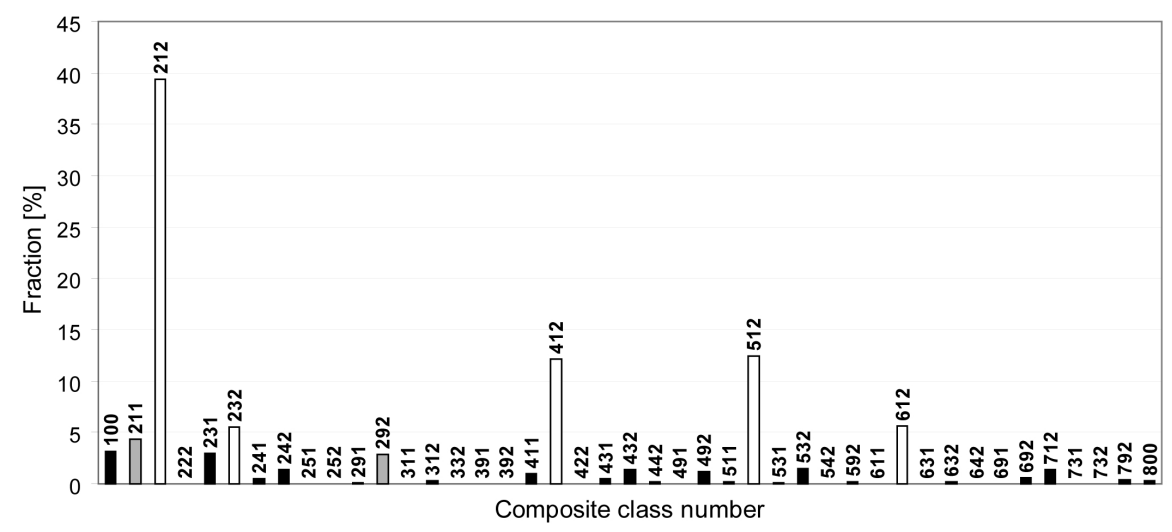

Fig. 4. Fractions $[\%]$ of the composite classes (combining land cover, topsoil and subsoil data) contained within the SMOS pixel around node 2002 029. Classes selected for the placement of network stations with fractions $>5 \%(212,232,412,512$ and 612$)$ are in white, the most frequent classes with high fraction of organic material (humus) in topsoil (292)/clay in subsoil (211) are in grey, and the remaining (not considered) classes are in black.

Table 4. Selected composite classes for the SMOS pixel around Discrete Global Grid node 2002 029: class number, land cover, top- and subsoil descriptions, respective class fractions [\%], corresponding recalculated fractions after redistribution of class 412 and omitting all other classes [\%], numbers of allocated network stations, and descriptive code $(\mathrm{A}=$ agriculture, $\mathrm{F}=$ forest, $\mathrm{H}=\mathrm{heath}, \mathrm{S}=\mathrm{sand}, \mathrm{L}=\mathrm{loamy}$ sand, $\mathrm{O}=$ organic material/humus).

\begin{tabular}{|c|c|c|c|c|c|c|c|}
\hline $\begin{array}{l}\text { Class } \\
\text { nr. }\end{array}$ & Land cover & Topsoil & Subsoil & Fract. & $\begin{array}{c}\text { Redist. } \\
\text { fract. }\end{array}$ & $\begin{array}{l}\text { Nr. } \\
\text { stats. }\end{array}$ & $\begin{array}{l}\text { Descr. } \\
\text { code }\end{array}$ \\
\hline 211 & Arable land & Coarse sand & Clay & 4.3 & 5.2 & 2 & ASC \\
\hline 212 & Arable land & Coarse sand & Sand & 39.4 & 55.3 & 16 & ASS \\
\hline 232 & Arable land & Coarse loamy sand & Sand & 5.5 & 6.7 & 2 & ALS \\
\hline 292 & Arable land & Organic material/humus & Sand & 2.9 & 3.5 & 2 & AOS \\
\hline 412 & Heterog. agricult. & Coarse sand & Sand & 12.1 & & & \\
\hline 512 & Forest & Coarse sand & Sand & 12.4 & 15.1 & 4 & FSS \\
\hline 612 & Heath/shrubs & Coarse sand & Sand & 5.6 & 14.2 & 4 & HSS \\
\hline Others & & & & 17.8 & & & \\
\hline
\end{tabular}

Soil samples were taken at each sensor depth during installation. Sand (2000-20 $\mu \mathrm{m})$, silt $(20-2 \mu \mathrm{m})$ and clay $(<2 \mu \mathrm{m})$ fractions (International Society of Soil Science, ISSS, 1929) of the $0-5 \mathrm{~cm}$ depth were determined for all network locations using sedimentation and sieve analysis, and soil bulk density was calculated (Table 6). Additionally, soil samples were collected from $0-5 \mathrm{~cm}$ depth on agricultural land, forest and heath (composite classes 212/ASS, 512/FSS and 612/HSS, respectively) during an airborne campaign (Bircher et al., 2012a). These samples were used for calibration checks over the entire wetness range in the laboratory.

\subsection{Network data analysis}

To check the feasibility of our approach as well as the reliability of the network data, several analyses were conducted:

The sensor output - sample water content couples from the lab calibration were compared to the Decagon 5TE default calibration curve (Topp et al., 1980). By means of the texture data the actual soil type distribution among the network stations was compared with the one based on the composite class map. Per station the measured soil moisture and temperature data of all depths for the year 2010 was checked for the expected behavior as a function of land cover and soil types.

Further network data analyses focused on the $0-5 \mathrm{~cm}$ depth only:

1. The soil moisture data of five selected agricultural stations $(2.09,3.08,3.01,1.09$, and 3.05, Fig. 2/Table 6) with vegetation types of comparable plant structure but decreasing clay (21-2\%)/increasing sand (51$95 \%$ ) fractions was compared with the 30 station network average in order to study the influence of texture for the time period January-August 2010 (to assure continuous data coverage). 
Table 5. Predominant crop types in the Skjern River Catchment, respective estimated fractions [\%], number of allocated network stations per crop type and per composite class individually (theoretical and actual distribution).

\begin{tabular}{lrrrrrr}
\hline $\begin{array}{l}\text { Crop } \\
\text { type }\end{array}$ & Fractions & $\begin{array}{r}\text { Nr. of } \\
\text { stations }\end{array}$ & $\begin{array}{r}\text { Nr. stat. } \\
\text { 211/ASC }\end{array}$ & $\begin{array}{r}\text { Nr. stat. } \\
\text { 212/ASS }\end{array}$ & $\begin{array}{r}\text { Nr. stat. } \\
\text { 232/ALS }\end{array}$ & $\begin{array}{r}\text { Nr. stat. } \\
\text { 292/AOS }\end{array}$ \\
\hline Spring barley & 28 & 8 & $2(1)$ & $2(4)$ & $2(1)$ & $2(1)$ \\
Winter barley & 7 & 2 & $0(0)$ & $2(2)$ & $0(0)$ & $0(0)$ \\
Grass & 20 & 5 & $0(1)$ & $5(3)$ & $0(1)$ & $0(0)$ \\
Winter wheat & 15 & 3 & $0(0)$ & $3(2)$ & $0(0)$ & $0(1)$ \\
Maize & 5 & 2 & $0(0)$ & $2(2)$ & $0(0)$ & $0(0)$ \\
Potatoes & 4 & 2 & $0(0)$ & $2(2)$ & $0(0)$ & $0(0)$ \\
Winter rape & 4 & & & & & \\
Oats & 2 & & & & & \\
Fallow land & 5 & & & & & \\
Others & 10 & & & & & \\
\hline
\end{tabular}
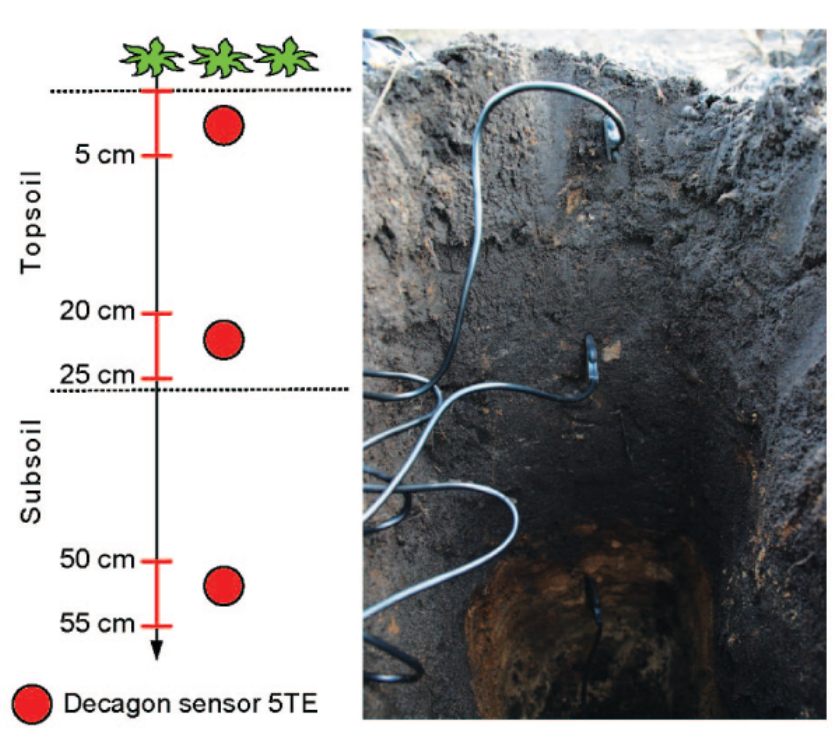

Fig. 5. Schematic sensor configuration at individual network stations (left) using three Decagon 5TE sensors integrating soil moisture over $\sim 5 \mathrm{~cm}$ depth intervals, respectively, and photo of soil profile with sensors installed according to the theoretical scheme (right).

2. To study regional variability and potential influence of the long-term precipitation gradient, soil moisture and temperature of three selected stations of similar texture and land cover in the north-east $(1.02,1.06,1.09)$ and south-west part $(3.02,3.04,3.07)$ of the SMOS pixel as well as precipitation data of the two closest $10 \mathrm{~km}$ grid nodes, respectively, were averaged and compared over the year 2010 .

3. Soil moisture and temperature averaged over all 30 network stations were compared with SMOS L2 soil moisture (initial guess and retrieved) and temperature (initial guess) data for the year 2010. Furthermore, to avoid deviations that may arise from the applied petrophysical relationship (Topp et al., 1980), this comparison was also conducted at the dielectric constant level. The 5TE sensor output was transformed to the real part of the dielectric constant by both the Decagon conversion (output/50) as well as an empirical relationship (real dielectr. $=0.0234 \cdot$ output -1.2917 , Rosenbaum et al., 2010), and averaged over all 30 network stations. With respect to SMOS, the real part of the dielectric constant from the L2 product (retrieved with a non cardioid model, Bengoa et al., 2010) computed from the retrieved soil moisture data by means of the Dobson dielectric mixing model was used.

\section{Results and discussion}

\subsection{Calibration and soil texture checks $(0-5 \mathrm{~cm})$}

Figure 6 shows the 5TE sensor output compared to the volumetric moisture content derived from $0-5 \mathrm{~cm}$ soil samples collected on agricultural land, forest and heath (composite classes 212/ASS, 512/FSS and 612/HSS, respectively) as well as the Decagon 5TE default calibration curve. Corresponding Root Mean Square Difference (RMSD) values are 0.030, 0.026 and 0.022 . Thus, for all three classes RMSDs are within the declared sensor accuracy (0.030).

In Fig. 7 the $0-5 \mathrm{~cm}$ depth texture data (sand- $\%$ vs. clay$\%$ ) for the network are shown and compared to the composite classes used in the Danish soil grid (Greve et al., 2007). As the organic content was not measured it is not possible to classify the two stations representing class 292/AOS. For the remaining 28 stations it can be seen that: (1) all forest and heath stations (classes 512/FSS and 612/HSS) are correctly allocated to the soil type sand, while two of the agriculture class 212/ASS (stations 2.04 and 2.08) exhibit slightly higher clay fractions than expected; (2) the agriculture class $211 /$ ASC is expected only to show more clay conditions in the subsoil, but in fact slightly and significantly higher clay 
Table 6. Overview of the 30 network stations: station number, latitude, longitude, composite class number/description, total sand, fine sand,

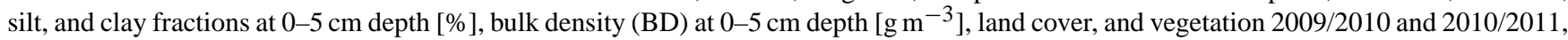
respectively.

\begin{tabular}{|c|c|c|c|c|c|c|c|c|c|c|c|}
\hline $\begin{array}{l}\text { Station } \\
\mathrm{Nr} \text {. }\end{array}$ & Lat & Lon & Class & $\begin{array}{l}\text { Sand } \\
\text { total }\end{array}$ & $\begin{array}{l}\text { Fine } \\
\text { sand }\end{array}$ & Silt & Clay & $\mathrm{BD}$ & $\begin{array}{l}\text { Land } \\
\text { cover }\end{array}$ & $\begin{array}{l}\text { Vegetation } \\
2009 / 2010\end{array}$ & $\begin{array}{l}\text { Vegetation } \\
2010 / 2011\end{array}$ \\
\hline 1.01 & 56.0193 & .1809 & 612/HSS & 94.3 & 18.9 & 3.5 & 1.2 & 1.29 & Heath & Grass & Grass \\
\hline 1.02 & 56.0376 & 9.1610 & 212/ASS & 91.7 & 21.4 & 5.4 & 2.3 & 1.32 & Agriculture & Grass/barley & Grass/barley \\
\hline 1.03 & 56.0283 & 9.1654 & 612/HSS & 91.5 & 11.1 & 2.4 & 4.1 & 1.43 & Heath & Scotch heather & Scotch heather \\
\hline 1.04 & 56.0733 & 9.3337 & 512/FSS & 87.3 & 7.0 & 4.2 & 3.0 & 1.04 & Forest & Spruce & Spruce \\
\hline 1.05 & 56.0330 & 9.1912 & 512/FSS & 82.5 & 15.3 & 4.4 & 3.6 & 1.02 & Forest & Spruce & Spruce \\
\hline 1.06 & 56.0513 & 9.1610 & 292/AOS & 90.0 & 16.1 & 4.6 & 2.8 & 1.20 & Agriculture & Spring barley & Potato \\
\hline 1.07 & 56.0426 & 9.1413 & 212/ASS & 90.0 & 20.3 & 5.4 & 3.5 & 1.31 & Agriculture & Grass & Grass \\
\hline 1.08 & 56.0466 & 9.1239 & 212/ASS & 82.2 & 8.9 & 5.3 & 3.3 & 1.21 & Agriculture & Potato & Winter barley \\
\hline 1.09 & 56.0360 & 9.1304 & 212/ASS & 89.5 & 13.3 & 4.6 & 3.2 & 1.30 & Agriculture & Winter barley & Spring barley \\
\hline 1.10 & 56.0348 & 9.2392 & 212/ASS & 93.2 & 14.6 & 3.6 & 2.7 & 1.19 & Agriculture & Maize & Maize \\
\hline 2.01 & 55.9398 & 9.2207 & 512/FSS & 95.8 & 9.3 & 1.8 & 1.3 & 1.33 & Forest & Spruce & Spruce \\
\hline 2.02 & 55.9839 & 9.1624 & 212/ASS & 90.5 & 8.9 & 4.0 & 2.4 & 1.04 & Agriculture & Grass & Grass \\
\hline 2.03 & 55.9816 & 9.1526 & 212/ASS & & 7.9 & & 1.0 & 1.28 & & & Spring barley \\
\hline 2.04 & 55.9759 & 9.0984 & 212/ASS & 87.3 & 20.9 & 4.9 & 7.1 & 1.21 & Agriculture & Potato & Spring barley \\
\hline 2.05 & 55.9763 & 9.0967 & 212/ASS & 87.3 & & & & 1.22 & & Spring & \\
\hline 2.06 & 55.9785 & 9.0871 & 212/ASS & 93.7 & 27.7 & 2.7 & 3.2 & 1.41 & Agriculture & Grass & Grass \\
\hline 2.07 & 55.9482 & 9.0337 & 212/ASS & 74.9 & 20.8 & 7.5 & 4.6 & 1.26 & Agriculture & Maize & (Winter) Rye \\
\hline 2.08 & 55.9398 & 9.0337 & 212/ASS & 86.3 & 52.1 & 7.2 & 6.4 & 1.04 & Agriculture & Winter wheat & Spring barley \\
\hline 2.09 & 55.9282 & 9.1153 & 232/ALS & 51.1 & 27.1 & 28.3 & 20.6 & 0.78 & Agriculture & Grass & Grass \\
\hline 2.10 & 55.9861 & 9.0907 & 612/HSS & 85.4 & 5.4 & 3.5 & 2.5 & 1.33 & Heath & Scotch heather & Scotch heather \\
\hline 2.11 & 55.9704 & 9.0225 & 612/HSS & 95.7 & 11.1 & 2.0 & 1.7 & 1.35 & Heath & Scotch heather & Scotch heather \\
\hline 3.01 & 55.8807 & 9.0142 & 211/ASC & 79.0 & 26.2 & 8.7 & 5.7 & 1.30 & Agriculture & Spring barley & Potato \\
\hline 3.02 & 55.9354 & 8.9221 & 212/ASS & 90.9 & 9.4 & 5.8 & 3.1 & 1.31 & Agriculture & Spring barley & Spring barley \\
\hline 3.03 & 55.9121 & 8.9462 & 212/ASS & 88.2 & 23.5 & 4.3 & 4.8 & 1.09 & Agriculture & Spring barley & Grass \\
\hline 3.04 & 55.9106 & 8.9357 & 212/ASS & 91.0 & 39.0 & 3.2 & 3.7 & 1.07 & Agriculture & Winter barley & Winter barley \\
\hline 3.05 & 55.9025 & 8.9175 & 212/ASS & 95.0 & 21.2 & 3.1 & 1.6 & 1.35 & Agriculture & Winter wheat & Spring barley \\
\hline 3.06 & 55.9115 & 8.8831 & 512/FSS & 88.9 & 14.2 & 5.0 & 4.8 & 1.16 & Forest & Spruce & Spruce \\
\hline 3.07 & 55.9096 & 8.8536 & 292/AOS & 92.1 & 15.7 & 3.8 & 4.0 & 0.99 & Agriculture & Winter wheat & Spring barley \\
\hline 3.08 & 55.8776 & 9.2683 & 211/ASC & 65.6 & 36.2 & 21.0 & 13.3 & 1.51 & Agriculture & Grass & Grass \\
\hline 3.09 & 55.8609 & 9.2945 & 232/ALS & 85.1 & 42.9 & 5.7 & 5.2 & 1.26 & Agriculture & Spring barley & Grass \\
\hline
\end{tabular}

fractions in the topsoil are found for stations 3.01 and 3.08, respectively; (3) with respect to agricultural class 232/ALS station 3.09 is correctly classified whereas station 2.09 shows significantly higher clay fractions than expected. Overall, five out of 28 stations are misclassified. However, overall the predetermined number of stations per soil type (Table 4) is more or less maintained in the final network setup.

\subsection{Profile soil moisture and temperature (all depths)}

Figure 8 shows soil and temperature data of all depths acquired during the year 2010 for five selected stations representing the majority of encountered patterns throughout the entire network data set: (a/f) 2.11 (heath, class 612/HSS), (b/g) 1.04 (forest, class 512/FSS), (c/h) 1.02 (agriculture, class 212/ASS, HOBE site Voulund), (d/i) 2.05 (agriculture, class 212/ASS), and (e/j) 2.09 (agriculture, class 232/ALS). Additionally, in case of the heath and forest stations (2.11 and 1.04) data from the sensors installed in the organic layers are depicted. It should be noted that for the organic material, site-specific calibration will be a crucial issue. Thus, at the point of writing this paper these measurements should only be considered in a relative term.

Typically, for all network locations in agricultural fields with coarse sand in the topsoil, a homogeneous mixture of loose sand and organic material is found in the plow layer with a pronounced hardpan just below $(\sim 30-45 \mathrm{~cm}$ depth), and with sand appearing at around $\sim 35-50 \mathrm{~cm}$ depth. Litter is absent or scarce. In most cases the $0-5 \mathrm{~cm}$ and $20-25 \mathrm{~cm}$ sensors were installed in the plow layer. Due to evapotranspiration in the surface layer and quick infiltration through the sandy material, the $0-5 \mathrm{~cm}$ sensors generally show drier conditions than the $20-25 \mathrm{~cm}$ sensors located just above the hardpan, which restricts the further downward movement of water. The $50-55 \mathrm{~cm}$ sensors located close to the upper hardpan boundary (Fig. 8c, station 1.02) measure higher water contents compared to the ones within or below the hardpan (Fig. 8d, station 2.05). 


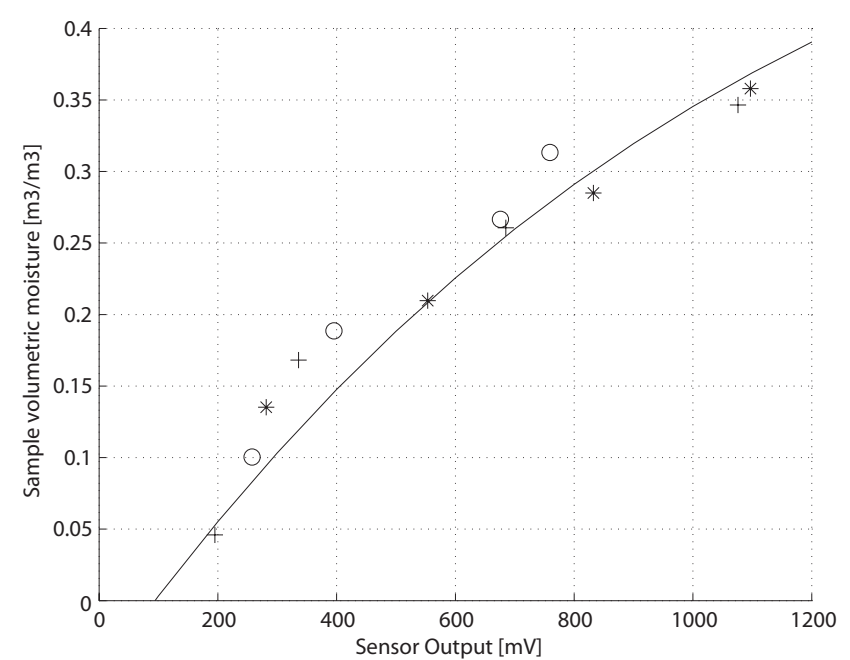

Fig. 6. 5TE sensor output $[\mathrm{mV}]$ against volumetric moisture content $\left[\mathrm{m}^{3} \mathrm{~m}^{-3}\right]$ derived from surface soil samples $(0-5 \mathrm{~cm}$ depth) of agricultural land $(\mathrm{o})$, forest $(+)$ and heath $(*)$ (composite classes 212/ASS, 512/FSS and 612/HSS, respectively) including the Decagon 5TE default calibration curve.

For the sandy soils under natural vegetation a pronounced litter layer of moss/organic material exists $(\sim 5-20 \mathrm{~cm})$. Due to absence of plowing, the topsoil is leached and quartz-rich as expected for a typical podsol, and the hardpan starts at around $20-25 \mathrm{~cm}$ depth. While all four forest stations show similar soil moisture patterns, the conditions at the four heath stations are very variable. Station 2.11 (Fig. 8a), for instance, is situated in a very wet area with standing water around the station. Nourished by the very moist moss/organic layer, the $0-5 \mathrm{~cm}$ sensor shows high moisture values. The $50-55 \mathrm{~cm}$ sensor was mounted below the water table which lowered during the season so that the effect of the dry sand below the hardpan became evident. In comparison, the sensors in the moss/organic and $0-5 \mathrm{~cm}$ mineral layers of the forest station 1.04 (Fig. 8b) are placed on a small hill and show much drier conditions. The $20-25 \mathrm{~cm}$ sensors of both stations 2.11 and 1.4 (Fig. 8a and b) were installed at the upper hardpan boundary and show similar behavior. Generally, the pattern of the forest stations is more related to the one met at agriculture sites where the $50-55 \mathrm{~cm}$ sensor is located in the dry sand below the hardpan (Fig. 8d, station 2.05).

At station 2.09 (Fig. 8e) the sensors were installed in clayey material with much higher water holding capacity and a firm hardpan at $20-25 \mathrm{~cm}$ depth. The water table is generally high and only decreased below $25 \mathrm{~cm}$ depth during the summer.

The different porosities of sandy and clayey soils are wellreflected in the measurements of the $50-55 \mathrm{~cm}$ sensors below the water table at station 2.11 and 2.9 (Fig. $8 \mathrm{a}$ and e) with saturated moisture contents of $\sim 0.4$ and 0.5 , respectively. Even higher values are found in the organic material. The effect

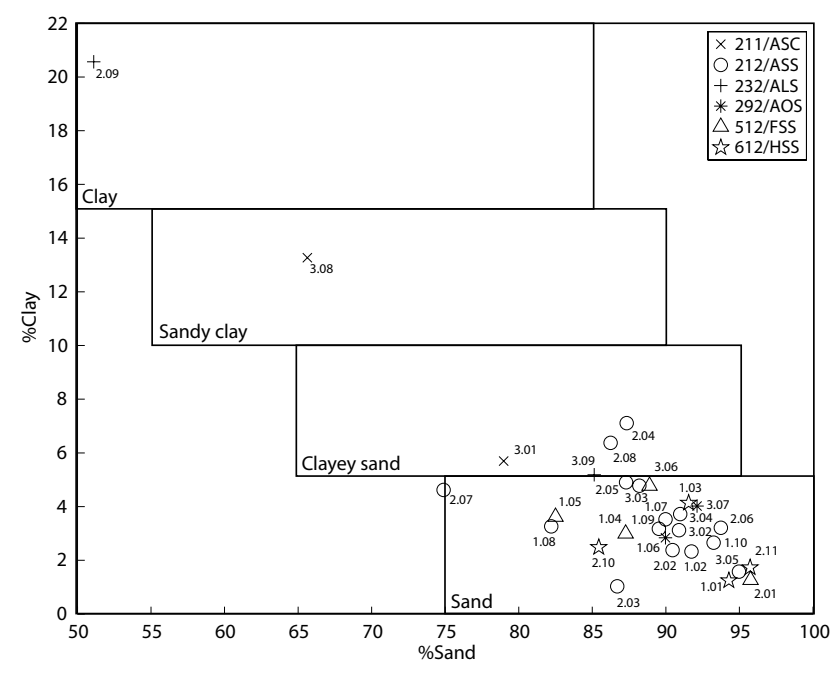

Fig. 7. Soil texture data (sand- $\%$ vs. clay- $\%$ of $0-5 \mathrm{~cm}$ depth) per network station according to the composite classes. Discrimination of zones corresponding to the Danish soil grid (Greve et al., 2007) is also shown.

of texture is also reflected in the seasonal variability of soil moisture which is relatively small for the sandy soils compared to clay and the organic material. Furthermore, irrigation has a distinct imprint as seen for the agricultural stations 1.02 and 2.05 (Fig. 8c and d), and in case of the forest site, tree interception must exert a balancing effect.

At all sites the temperature profiles show the expected diurnal and seasonal patterns, as well as a slight time lag and amplitude decrease with increasing depth. Furthermore, an isolation effect due to the presence of vegetation and moss/organic layers is visible in both the diurnal and seasonal temperature amplitudes of the mineral soil at the heath and forest stations, most pronounced in case of the latter.

All in all, the observed moisture and temperature patterns are clearly related to land cover and soil conditions. Soil moisture seems to be mostly affected by soil characteristics while soil temperature mostly dependent on land cover.

\subsection{Surface soil moisture and temperature $(0-5 \mathrm{~cm})$}

\subsubsection{Texture comparison}

Figure 9a illustrates the $0-5 \mathrm{~cm}$ soil moisture measurements of the agricultural stations 2.09, 3.08, 3.01, 1.09 and 3.05 with similar vegetation and decreasing clay/increasing sand fractions (Table 6), respectively, in comparison with the 0 $5 \mathrm{~cm}$ average over all 30 stations between January and $\mathrm{Au}-$ gust 2010. The mean of daily precipitation of the $10 \mathrm{~km}$ grid nodes contained within the SMOS pixel (Fig. 1) is plotted in Fig. $9 b$.

Over the major part of the chosen time span, increasing clay content complies with higher moisture content, resulting in significant overrepresentation with respect to the overall 

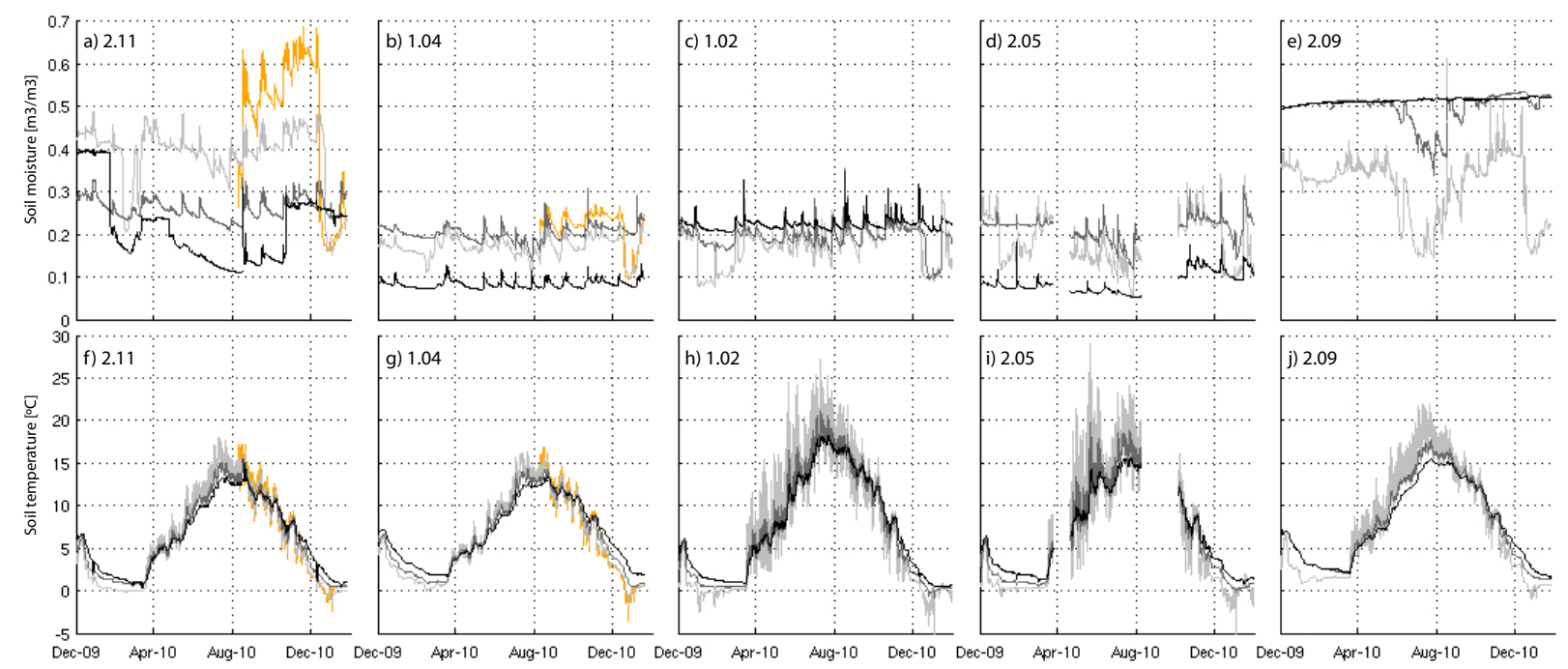

Fig. 8. Profiles of soil moisture (a-e) and temperature (f-j) for the year 2010: for stations (a/f) 2.11 (heath, class 612/HSS), (b/g) 1.04 (forest, class 512/FSS), (c/h) 1.02 (agriculture, class 212/ASS, HOBE site Voulund), (d/i) 2.05 (agriculture, class 212/ASS), and (e/j) 2.09 (agriculture, class 232/ALS); organic layer (orange), mineral soil: 0-5 cm (light grey), 20-25 cm (dark grey), and 50-55 cm (black) depths.

network average, and vice versa in the case of high sand contents. Thus, the influence of soil texture is clearly demonstrated and also reflected in the biases (average residuals from expected value) ranging from 0.146 for the clay station 2.09 to -0.057 for station 3.05 with highest sand fractions. The larger absolute bias (relative to other stations) of the clay station is reasonable, as the 30 station average contains a much larger fraction of sandy sites. The moisture pattern also follows the precipitation trend well. The significant increases in the soil moisture not reflected in the precipitation measurements in the first half of March are due to snow melt. Further such increases during the growing season can be ascribed to irrigation. In contrast, rain events not apparent in some of the soil moisture measurements can be attributed to the fact that soil moisture of single stations is plotted while the shown precipitation is an average over all DMI $10 \mathrm{~km}$ grid nodes contained within the studied SMOS pixel. In some cases, the area on average received a considerable amount of precipitation while a single station was not struck by a certain precipitation event.

\subsubsection{Regional comparison}

Figure 10 shows average and standard deviation (shaded region) of the (a) $0-5 \mathrm{~cm}$ soil moisture and (b) $0-5 \mathrm{~cm}$ soil temperature of three selected stations of similar texture and land cover in the north-east $(1.02,1.06,1.09)$ and south-west part $(3.02,3.04,3.07)$ of the SMOS pixel, as well as (c) daily precipitation of the two closest $10 \mathrm{~km}$ grid nodes, respectively, for the year 2010.

RMSD/biases between the two areas are low with values of $0.034 / 0.010,0.86 / 0.11^{\circ} \mathrm{C}$ and $3.72 /-0.39 \mathrm{~mm}$ for soil moisture, temperature and precipitation, respectively, with considerable correlations reflected in corresponding $R^{2}$ values of $0.57,0.99$ and 0.86 . Thus, regional differences are most pronounced for soil moisture and least for temperature. While soil temperature is known to be a rather conservative parameter, the particularly low spatial variability of precipitation was confirmed in a data check of the mean of daily precipitation of the DMI $10 \mathrm{~km}$ grid nodes contained within the studied SMOS pixel (not shown). It can be explained by the fact that precipitation is often arriving in fronts from the Atlantic, passing rather homogeneously over the area. More local convective events are not very frequent and there are no mountains to disturb the flow of the currents. Meanwhile, the spatial variability of soil moisture is known to be high due to a combination of different natural influencing factors acting at different spatial scales as well as irrigation, which is applied spatially variable in terms of timing and amount of water.

Temporal mean standard deviations over the entire year are 0.024 and 0.041 (soil moisture) and 0.37 and $0.5^{\circ} \mathrm{C}$ (soil temperature) for the three north-eastern and south-western stations, respectively. They can be interpreted as indications of the spatial variability within the two regions. Meanwhile the RMSD reflects the average deviation of the behavior in one area to the other over the year. The fact that standard deviations and RMSD are in the same range suggests that the variability between the two areas is in the same order as within them. 

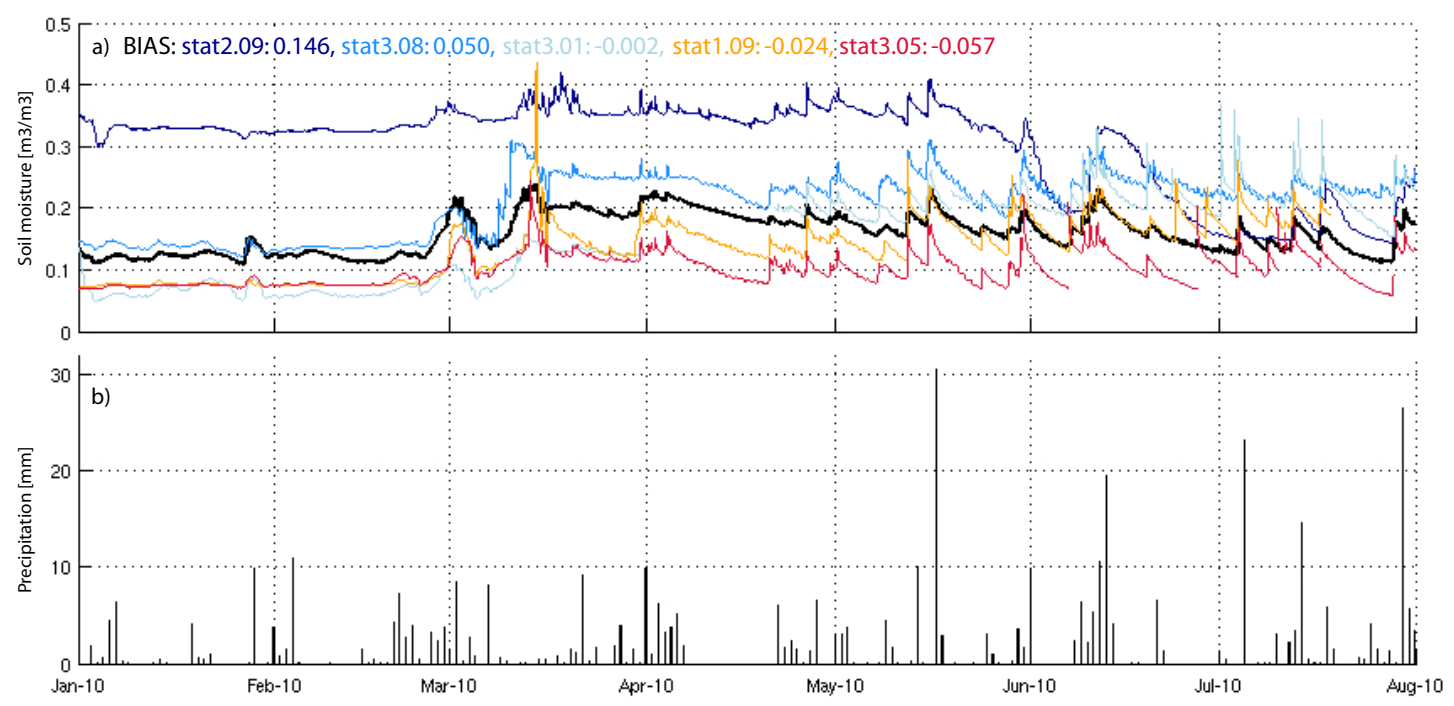

Fig. 9. (a) Surface soil moisture $(0-5 \mathrm{~cm})$ with decreasing/increasing clay/sand fractions, respectively, between January and August 2010: agricultural stations 2.09 (dark blue), 3.08 (blue), 3.01 (light blue), 1.09 (orange) and 3.05 (red) compared to the average of all 30 network stations (black) including corresponding biases; and (b) mean of daily precipitation of the DMI $10 \mathrm{~km}$ grid nodes contained within the SMOS pixel.

\subsubsection{SMOS L2 comparison}

Figure 11 displays $0-5 \mathrm{~cm}$ average network and SMOS (a) soil moisture and (b) temperature data (L2 product) for the year 2010, as well as (c) the corresponding mean of daily precipitation of the DMI $10 \mathrm{~km}$ grid nodes contained within the SMOS pixel (Fig. 1).

Also network soil moisture spatial variability (standard deviation, blue-shaded region) and in situ sensor accuracy are shown (grey-shaded region). For SMOS the retrieved soil moisture values including the associated Data Quality indeX (DQX) reflecting the retrieval error induced by the model (red-shaded region) as well as the initial guess are shown. The temporal variability in the observation period is in the order of 0.041 , which corresponds to the standard deviation of mean network soil moisture fluctuating around a temporal average of 0.176 . The spatial variability between the individual stations is larger with a temporal average of 0.070 . This is in the same order as found by Famiglietti et al. (2008) for a site in the United States at the same spatial scale. Network and SMOS soil moisture follow the precipitation dynamics well. Correlations $\left(R^{2}\right)$ between network and SMOS retrieved and initial guess soil moisture, respectively are 0.49 and 0.67 . However, remarkable offsets are visible. While the SMOS soil moisture initial guess approximately corresponds to the upper boundary of the network variability error bar, the retrieved data follows more or less its lower boundary, or is even below (bias values of 0.057/-0.092 for initial/retrieved SMOS soil moisture compared to the network average, respectively). Furthermore,
SMOS soil moisture shows higher amplitude compared to the network data. These findings are consistent with results from various validation sites across continents: Australia (Rüdiger et al., 2011), Germany (Dall'Amico et al., 2011), USA (Jackson et al., 2011; Al Bitar et al., 2012; Leroux et al., 2012) report positive biases in the order of $0.05-0.15$ and negative biases around $0.02-0.2$ for SMOS initial and retrieved soil moisture, respectively. The temporal trends encountered at the individual sites are followed by the retrieved SMOS soil moisture $\left(R^{2} \sim 0.4-0.62\right)$, and tendencies of the latter to overestimate the dynamics (larger amplitudes) have also been noted. Only in Africa constant soil moisture overestimation by SMOS was found (Gruhier et al., 2012).

In case of temperature, the average of the 30 network stations and the SMOS initial guess surface temperature are in good agreement with corresponding RMSD, bias and $R^{2}$ values of $1.1^{\circ} \mathrm{C},-0.2{ }^{\circ} \mathrm{C}$ and 0.97 , respectively. Thus, no significant error seems to be introduced from this parameter.

The comparison of the real dielectric constant averaged from the network and for SMOS over the year 2010 reveal RMSD, bias and $R^{2}$ values of 3.95/4.30, 2.30/3.33 and 0.49/0.49 for the Decagon/Rosenbaum et al. (2010) sensor output-dielectric constant relations, respectively. Consequently, there is no distinct difference between the two dielectric models with $R^{2} \mathrm{~s}$ equal to that for the soil moisture comparison. As the SMOS dielectric constant is computed from retrieved soil moisture by means of the Dobson model, this implies that at both comparison levels the uncertainty is consistent and remains on either the network or the SMOS data side. 

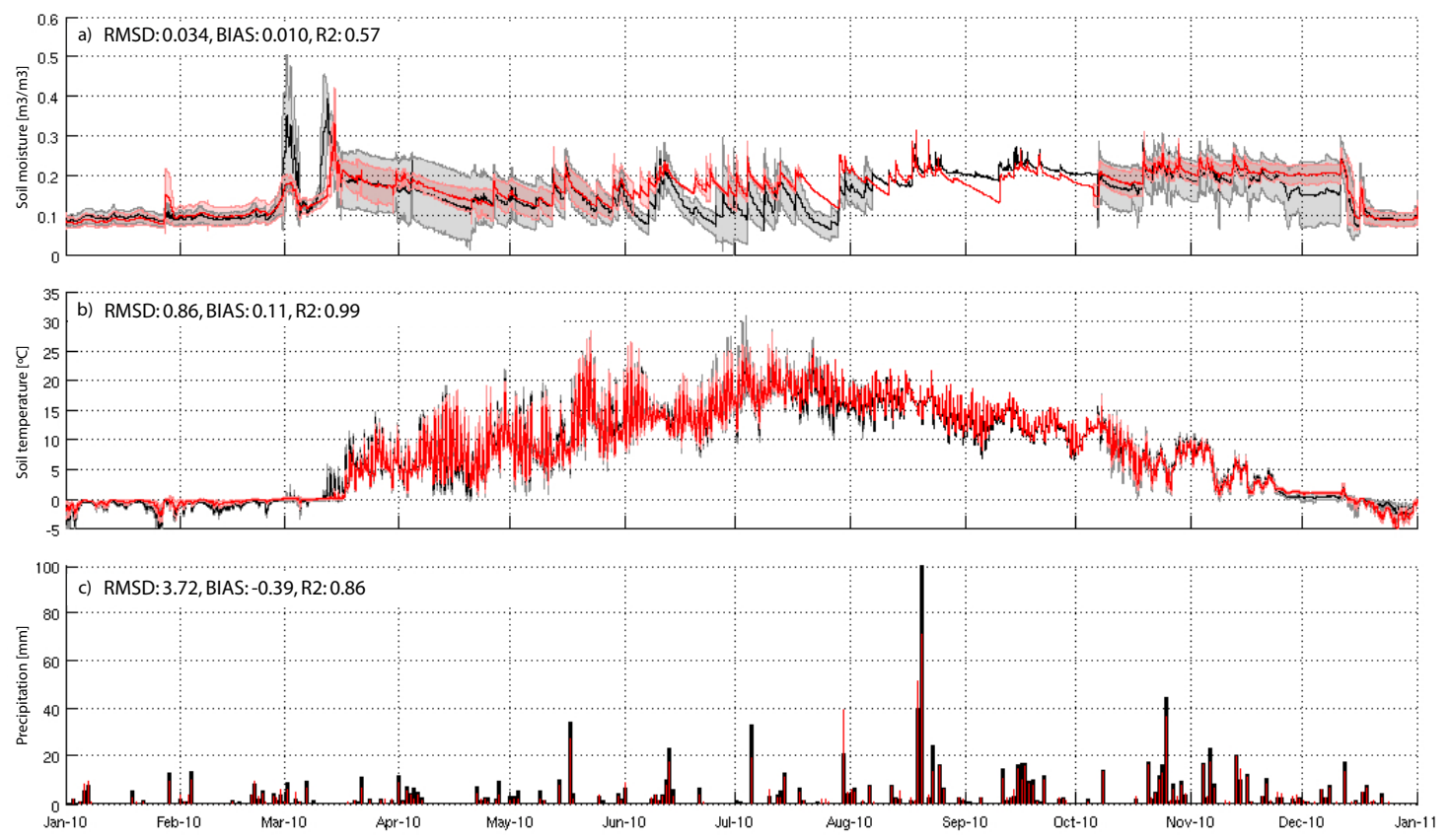

Fig. 10. Regional surface soil moisture and temperature $(0-5 \mathrm{~cm})$ for the year 2010: Average and standard deviation (shaded regions) of the 0-5 cm soil moisture (a) and 0-5 cm soil temperature (b) of three selected stations of similar texture and land cover in the north-east (1.02, 106, 1.09, red) and south-west part (3.02, 3.04, 3.07, black) of SMOS pixel 2002029 as well as daily precipitation (c) of the two closest $10 \mathrm{~km}$ grid nodes, respectively, including corresponding RMSD, bias and $R^{2}$ values. During periods where the shaded regions are absent, only one sensor was operational per area.

Additionally, Bircher et al. (2012b) present a study where the network stations were grouped after (a) soil types, (b) land cover classes, and (c) composite class numbers. The respective averages were compared to corresponding SMOS L2 soil moisture data. It turned out that amongst all of these subgroups only the soil type sand class achieved as good statistical results as the entire network average. As the sand class includes about $80 \%$ of the stations, it is not further surprising that it behaves very similarly. In any case, the fact that none of the subgroups performs significantly better than the network average enhances our confidence in the representativeness of the chosen network setup.

The results of the presented network data analyses together with the fact that our findings from the comparison with SMOS data are well in range with worldwide validation results, demonstrate similar performance as several other networks. We thus consider the Danish network to likewise operate according to expectations and to be well-suited for SMOS validation. Certainly, the discrepancies between network and retrieved SMOS soil moisture data need to be more closely investigated at the Danish site. Currently, the agreement between the initial guess soil moisture (ECMWF model) and in situ observations is higher than the one retrieved by SMOS. In this regard, we should keep in mind that SMOS has only been launched two years ago while the ECMWF model has become well established in the course of many more years of research. This, together with the progress SMOS data quality has made since launch, we believe that by means of persistent feedback from validation activities, it is very likely that it will continue improving in the near future.

At the moment, numerous explanations for the deviations between SMOS and in situ data are worldwide under discussion: (1) a mismatch between sampling depth of conventional soil moisture sensors $(\sim 5-7 \mathrm{~cm})$ and the depth contributing to L-band soil emission ( $<5 \mathrm{~cm}$, Escorihuela et al., 2010), (2) scale effects due to the large disparity in spatial scale between the SMOS and in situ measurements, (3) inaccuracies in the SMOS retrieval algorithm and related input, (4) inacurracies in the in situ measurements, and (5) RFI contamination. It is likely, that the observed deviations result from a combination of these factors with variable shares depending on a validation site's environmental conditions as well as the chosen measurement setup. At the Danish validation site investigations are underway to separate the respective contributions. While we believe to reduce the probability of scaling effects by means of the carefully chosen network setup, we see inaccuracies in the SMOS retrieval algorithm and RFI contamination as most likely error sources. Currently, the replacement of the Dobson dielectric mixing model with the one of Mironov et al. (2004) is for example under investigation. Bircher et al. (2012a) showed that Mironov performed 

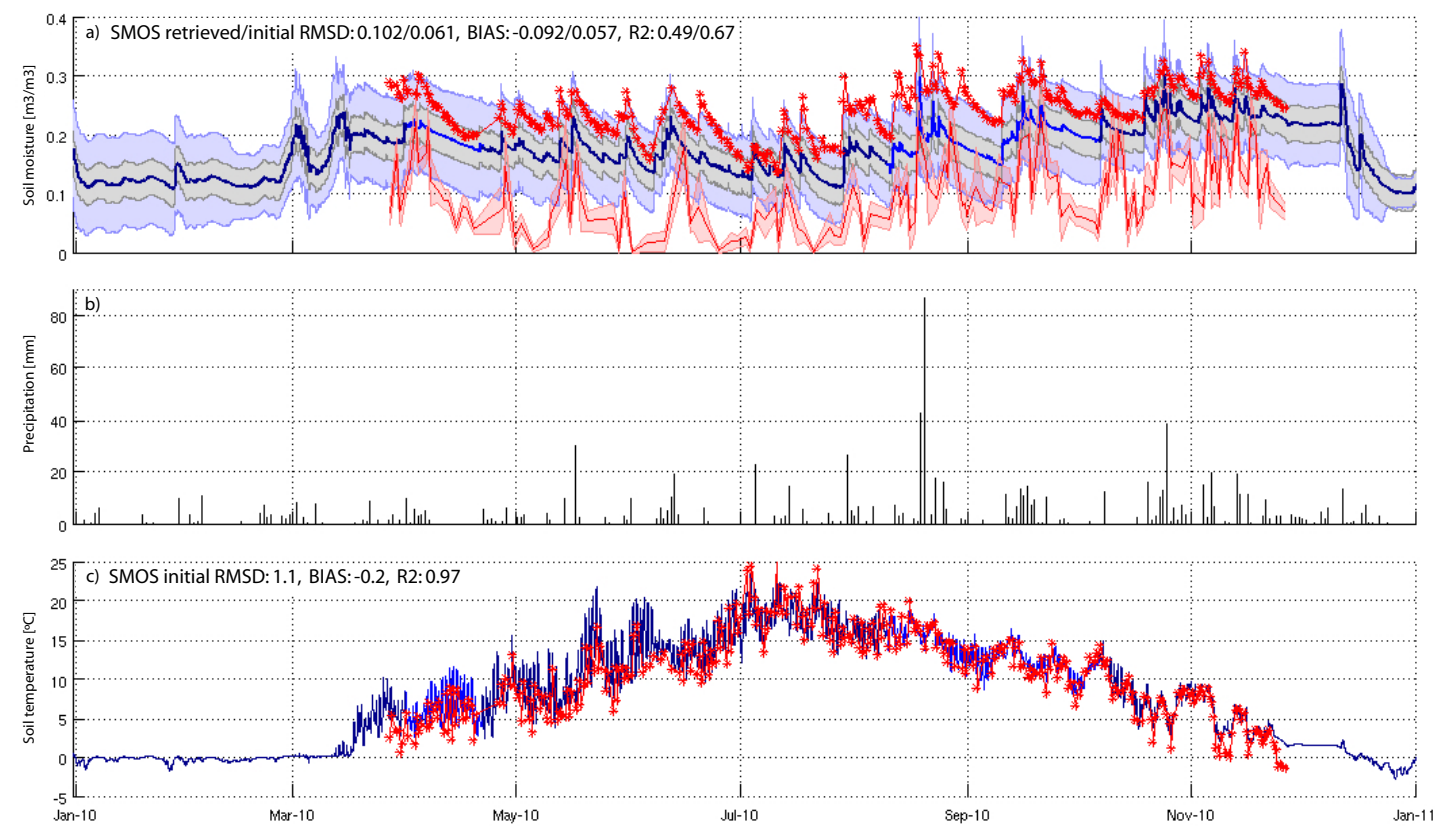

Fig. 11. Surface soil moisture and temperature $(0-5 \mathrm{~cm})$ comparison between network and SMOS for the year 2010: (a) surface soil moisture network average and standard deviation (blue lines* and shaded region) including sensor accuracy (grey-shaded region), and retrieved SMOS soil moisture (red line) including the associated retrieval error estimate (DQX, red-shaded region) and corresponding initial guess (red stars); (b) mean of daily precipitation of the DMI $10 \mathrm{~km}$ grid nodes contained within the SMOS pixel; (c) surface soil temperature network average (blue lines) and SMOS initial guess (red stars). RMSD, bias and $R^{2}$ of the in situ versus retrieved/initial SMOS data for soil moisture and temperature are indicated.

better at the Danish validation site to bring brightness temperatures modeled from in situ soil moisture data in agreement with airborne brightness temperature measurements at the $2 \times 2 \mathrm{~km}^{2}$ scale. Thus, it is also likely that the deviances between SMOS and in situ soil moisture could be lowered by using Mironov in the SMOS retrieval algorithm. Furthermore, in a subsequent study (Bircher et al., 2012b), SMOS data was filtered based on quality parameters contained in the L2 product which showed very good correspondence with an RFI detection scheme based on L1A data (Anterrieu , 2011). Comparing the filtered SMOS data with the network average improved the correlation significantly, nearly meeting up with the one for the ECMWF model. Meanwhile, the bias only decreased slightly. We assume that through the filtering overpasses of heavy RFI contamination are removed, while the remaining bias could at least partly be due to permanent low energy RFI pollution (soft RFI) still present in the data. Investigations on this subject are ongoing. With respect to the high amplitudes in the retrieved SMOS data, there is generally consensus that they are likely to be attributed to the mismatch in sampling depth. Generally, the very top layer shows a rapid soil moisture increase immediately following rain events, succeeded by a fast decrease as a result of evaporation and infiltration processes. At deeper depths this response is delayed and somewhat less. The wetter and the more sandy the soils, the more pronounced this effect is. A study is currently conducted to analyze this issue.

\section{Conclusions}

A soil moisture and temperature network with 30 stations (sensors at $0-5,20-25$ and $50-55 \mathrm{~cm}$ depths plus in the organic layer in the case of heath/forest locations) has been established within one SMOS pixel $\left(44 \times 44 \mathrm{~km}^{2}\right)$ in the Skjern River Catchment, Western Denmark.

As a sufficiently long pre-study with a dense enough setup for the determination of time stable sites was impossible, a comparably high station number was chosen based on the findings from different studies carried out at other test sites. Furthermore, careful analysis of soil moisture influencing variables and the SMOS retrieval concept including the SMOS data arrangement over the area preceded the installation of the sensors. This network design phase included the following steps: (1) the selection of SMOS pixel 2002029 with minimal water fraction and maximal catchment coverage, (2) the arrangement of three network clusters along a long-term precipitation gradient centered at the SMOS node, and (3) the distribution of the stations according to respective fractions of six classes combining $82 \%$ of the prevailing land cover, top- and subsoil conditions. In case of agriculture, additionally crop type frequency was considered.

Analysis of the collected network data during the year 2010 showed that soil moisture generally follows the precipitation trend. Furthermore, soil moisture and temperature patterns were relatable to the respective land cover and 
soil conditions. The high soil moisture variability throughout the stations seems to be a strong function of texture/structure while to a less extent influenced by land cover. At the same time the variability in soil temperature is less pronounced and merely a function of the latter. Regional differences in $0-5 \mathrm{~cm}$ soil moisture, temperature and precipitation between the north-east and south-west turned out to be small.

A first comparison between $0-5 \mathrm{~cm}$ network averages and the SMOS L2 product showed comparable trends with $R^{2}$ of $0.49 / 0.67$ and 0.97 for SMOS retrieved/initial soil moisture and initial temperature, respectively. The two former indicate significant under-/overrepresentation of the network data (biases of $-0.092 / 0.057 \mathrm{~m}^{3} \mathrm{~m}^{-3}$ ) as well as faster and stronger wetting/dry-downs (larger amplitudes). Correlation with precipitation is traceable in both, network and SMOS soil moisture data. Average network and SMOS soil temperatures are in good agreement with $R^{2}$ of 0.97 and a bias of $-0.2{ }^{\circ} \mathrm{C}$. Thus, this parameter should not introduce errors in the soil moisture retrieval process.

Based on the above findings together with the fact that our SMOS data comparison is well in range with worldwide validation results, we consider the network to operate according to expectations and to be well-suited for SMOS validation. A subsequent study (Bircher et al., 2012b) showed that in case of soil moisture subgroups of the network stations based on different criteria (e.g. soil type, land cover and composite classes) did not achieve as good statistical results as the entire network average when compared with SMOS data. All of the above supports our presumption that through (1) constraining the network to one selected SMOS pixel in order to avoid error-prone interpolation of SMOS data before comparison with the ground data, and (2) consideration of the most soil moisture influencing variables in the choice of network station locations right from the start rather than choosing a random solution, the representativeness of the network setup is a priori enhanced. Thus, it endorses the validity of our approach to obtain a representative large-scale in situ soil moisture average for comparison with SMOS data.

Extensive validation activities are currently ongoing at the Danish validation site. It is likely that the discrepancies between network and SMOS soil moisture result from a combination of several factors. The investigation of these potential error sources and their respective contributions is subject of subsequent studies. Furthermore, the influence of the organic layers under natural vegetation is planned to be addressed.

The network data will soon be available to the scientific community from the ISMN database (www.ipf.tuwien.ac.at/ insitu/).
Acknowledgements. The project was funded by the Villum Foundation and the Technical University of Denmark. Special thank goes to Yann Kerr and his team at CESBIO, and Jean-Pierre Wigneron for constructive discussions. We also gratefully appreciate various support of the HOBE project members throughout this work. The authors would also like to thank the reviewers for their extensive and constructive feedback which helped improving the quality of the article.

Edited by: N. Verhoest

\section{References}

Al Bitar, A., Leroux, D., Kerr, Y. H., Merlin, O., Richaume, P., Sahoo, A., and Wood, E. F.: Evaluation of SMOS Soil Moisture products over continental U.S. using the SCAN/SNOTEL network, IEEE T. Geosci. Remote, 50, 15721586, doi:10.1109/TGRS.2012.2186581, 2012.

Albergel, C., Rüdiger, C., Pellarin, T., Calvet, J.-C., Fritz, N., Froissard, F., Suquia, D., Petitpa, A., Piguet, B., and Martin, E.: From near-surface to root-zone soil moisture using an exponential filter: an assessment of the method based on in-situ observations and model simulations, Hydrol. Earth Syst. Sci., 12, 1323-1337, doi:10.5194/hess-12-1323-2008, 2008.

Anterrieu, E.: On the detection and quantification of RFI in L1A signals provided by SMOS, IEEE T. Geosci. Remote, 49, 39863992, 2011.

Bardossy, A. and Lehmann, W.: Spatial distribution of soil moisture in a small catchment, Part 1: geostatistical analysis, J. Hydrol., 206, 1-15, 1998.

Bengoa, B., Zapata, M., Cabeza, C., and Rodriguez, M.: SMOS Level 2 processor and Auxiliary Data Products Specifications, Tech. Rep. SO-TN-IDR-GS-0006, V5.3, INDRA, Madrid, available at: http://www.cesbio.ups-tlse.fr/fr/smos/smos_data_ info.html (last access: 20 January 2011), 2010.

Bircher, S., Balling, J., and Skou, N.: SMOS validation activities at different scales in the Skjern River Catchment, Western DK, in: ESA Living Planet Symposium, edited by: Lacoste-Francis, H., ESA, ESA communications, Bergen, Norway, 2010.

Bircher, S., Balling, J. E., Skou, N., and Kerr, Y.: Validation of SMOS brightness temperatures during the HOBE airborne campaign, Western Denmark, IEEE T. Geosci. Remote, 50, 14681482, doi:10.1109/TGRS.2011.2170177, 2012a.

Bircher, S., Skou, N., and Kerr, Y.: Validation of SMOS L1C and L2 products and important parameters of the retrieval algorithm in the Skjern River Catchment, Western Denmark, IEEE T. Geosci. Remote, in review, 2012b.

Bogena, H., Herbst, M., Huisman, J. A., Rosenbaum, U.,Weuthen, A., and Veerecken, H.: Potential of wireless sensor networks for measuring soil water content variability, Vadose Zone J., 9, 1002-1013, 2010.

Bornebusch, C. and Milthers, K.: Jordbundskort over Danmark, 1:500.000, Danmarks Geologiske Undersoegelse, (III) 24, 68 pp., 1935.

Bosch, D., Lakshmi, V., Jackson, T., Choi, M., and Jacobs, J.: Large scale measurements of soil moisture for validation of remotely sensed data: Georgia soil moisture experiment of 2003, J. Hydrol., 323, 120-137, 2006. 
Bossard, M., Feranec, J., and Otahel, J.: CORINE land cover technical guide - Addendum 2000, Tech. Rep. 40, European Environmental Agency, Copenhagen, available at: http://www. eea.europa.eu/publications/tech40add (last access: 7 July 2009), 2000.

Brocca, L., Morbidelli, R., Melone, F., and Moramarco, T.: Soil moisture spatial variability in experimental areas of central Italy, J. Hydrol., 333, 356-373, 2007.

Brocca, L., Melone, F., Moramarco, T., and Morbidelli, R.: Spatial-temporal variability of soil moisture and its estimation across scales, Water Resour. Res., 46, W02516, doi:10.1029/2009WR008016, 2010.

Calvet, J.-C., Fritz, N., Froissard, F., Suquia, D., Petitpa, A., and Piguet, B.: In situ soil moisture observations for the CAL/VAL of SMOS: the SMOSMANIA network, Conference Proceedings of the IEEE International Geoscience and Remote Sensing Symposium (IGARSS), 23-28 July 2007, Barcelona, Spain, 1196-1199, 2007.

Champagne, C., Berg, A., Belanger, J., McNairn, H., and de Jeu, R.: Evaluation of soil moisture derived from passive microwave remote sensing over agricultural sites in Canada using groundbased soil moisture monitoring networks, Int. J. Remote Sens., 31, 3669-3690, 2010.

Cosh, M., Jackson, T., Bindlish, R., and Prueger, J. H.: Watershed scale temporal and spatial stability of soil moisture and its role in validating satellite estimates, Remote Sens. Environ., 92, 427435, 2004

Crow, W. T., Ryu, D., and Famiglietti, J. S.: Upscaling of field-scale soil moisture measurements using distributed land surface modeling, Adv. Water Resour., 28, 1-14, 2005.

dall'Amico, J. T., Schlenz, F., Loew, A., and Mauser, W.: First results of SMOS soil moisture validation in the Upper Danube Catchment, IEEE T. Geosci. Remote, 50, 1507-1516, doi:10.1109/TGRS.2011.2171496, 2012.

Danmarks Statistik, A. and Service, H.: Cultivated area by unit, region, crop and time in hectares for the region Midtjylland, available at: www.statistikbanken.dk (last access: 10 June 2009), 2009.

De Lannoy, G. J. M., Houser, P. R., Verhoest, N. E. C., Valentijn, V. R. N., and Gish, T. J.: Upscaling of point soil moisture measurements to field averages at the OPE test site, J. Hydrol., 343, 1-11, 2007.

de Rosnay, P., Gruhier, C., Timouk, F., Baup, F., Mougin, E., Hiernaux, P., Kergoat, L., and LeDantec, V.: Multi-scale soil moisture measurements at the Gourma meso-scale site in Mali, J. Hydrol., 375, 241-252, 2009.

Decagon Devices, I.: ECH2O data collection system. Operator's manual for models Em50/Em50R, Decagon Devices, Inc., 2365 NE Hopkins Court Pullman WA 99163 USA, 6th Edn., 2002.

Decagon Devices, I.: ECH2O soil moisture sensor. Operator's manual for model 5TE, Decagon Devices, Inc., 2365 NE Hopkins Court Pullman WA 99163 USA, 3rd Edn., 2008.

Dobson, M., Ulaby, F., Hallikainen, M., and El-Reyes, M.: Microwave dielectric behavior of wet soil - Part II: Dielectric mixing models, IEEE T. Geosci. Remote, 23, 35-46, 1985.

Dorigo, W. A., Wagner, W., Hohensinn, R., Hahn, S., Paulik, C., Xaver, A., Gruber, A., Drusch, M., Mecklenburg, S., van Oevelen, P., Robock, A., and Jackson, T.: The International Soil Moisture Network: a data hosting facility for global in situ soil mois- ture measurements, Hydrol. Earth Syst. Sci., 15, 1675-1698, doi:10.5194/hess-15-1675-2011, 2011.

EEA: Corine land cover 2000 (CLC2000) $100 \mathrm{~m}$ - version 8/2005, available at: http://dataservice.eea.eu.int/ (last access: 2 March 2006), 2005.

Escorihuela, M., Chanzy, A., Wigneron, J., and Kerr, Y.: Effective soil moisture sampling depth of L-band radiometry: A case study, Remote Sens. Environ., 114, 995-1001, 2010.

Famiglietti, J. S., Rudnicki, J. W., and Rodell, M.: Variability in surface moisture content along a hillslope transect: Rattlesnake Hill, Texas, J. Hydrol., 210, 259-281, 1998.

Famiglietti, J. S., Devereaux, J., Laymon, C., Tsegaye, T., Houser, P., Jackson, T., Graham, S., Rodell, M., and van Oevelen, P. Ground-based investigations of soil moisture variability within remote sensing footprints during the Southern Great Plains 1997 (SGP97) Hydrology Experiment, Water Resour. Res., 35, 1839 1851, 1999.

Famiglietti, J. S., Ryu, D., Berg, A. A., Rodell, M., and Jackson, T. J.: Field observations of soil moisture variability across scales, Water Resour. Res., 44, W01423, doi:10.1029/2006WR005804, 2008.

FAO-AQUASTAT: Review of world water resources by country, available at: http://www.fao.org/nr/water/aquastat/main/index stm (last access: 1 December 2009), 2003.

Friesen, J., Rodgers, C., Oguntunde, P. G., Hendrickx, J. M. H., and van de Giesen, N.: Hydrotope-based protocol to determine average soil moisture over large areas for satellite calibration and validation with results from an observation campaign in the Volta Basin, West Africa, IEEE T. Geosci. Remote, 46, 1995-2004, 2008.

FVM: Information on crops on field level from the Ministry of Food, Fisheries and Agriculture (FVM) regarding application for single-payments in 2005, accessed via the research-based agricultural registry at The Faculty of Agriculture, Aarhus University, 2005.

Greve, M. H., Greve, M. B., Bøcher, P., Balstrøm, T., BreuningMadsen, H., and Krogh, L.: Generating a Danish raster-based topsoil property map combining choropleth maps and point information, Danish Journal of Geography, 107, 1-12, 2007.

Gruhier, C., Pellarin, T., de Rosnay, P., and Kerr, Y.: SMOS soil moisture product evaluation over West-Africa at local and regional scale, Remote Sens. Environ., in review, 2012.

ISSS: Minutes of the First Commission Meetings, in: Proceedings of the International Society of Soil Science, Vol. 4, 215-220, International Society of Soil Science (ISSS), Washington, USA, 1929.

Jackson, T. J., Cosh, M. H., Bindlish, R., Starks, P. J., Bosch, D. D., Seyfried, M., Goodrich, D. C., Moran, M. S., and Du, J.: Validation of Advanced Microwave Scanning Radiometer soil moisture products, IEEE T. Geosci. Remote, 48, 4256-4272, 2010.

Jackson, T. J., Bindlish, R., Cosh, M. H., Zhao, T., Starks, P. J., Bosch, D. D., Seyfried, M., Moran, M. S., Goodrich, D. C., Kerr, Y. H., and Leroux, D.: Validation of Soil Moisture and Ocean Salinity (SMOS) soil moisture over watershed networks in the U.S., IEEE T. Geosci. Remote, 50, 1530-1543, doi:10.1109/TGRS.2011.2168533, 2012.

Jarvis, A., Reuter, H., Nelson, A., and Guevara, E.: Hole-filled seamless SRTM, data V4, available at: http://srtm.csi.cgiar.org (last access: 26 June 2009), 2008. 
Jensen, K. and Illangasekare, T.: HOBE: A Hydrological Observatory, Vadose Zone J., 10, 1-7, 2011.

Kerr, Y. H., Waldteufel, P., Wigneron, J.-P., Martinuzzi, J.-M., Font, J., and Berger, M.: Soil moisture retrieval from space: The soil moisture and ocean salinity (SMOS) mission, IEEE T. Geosci. Remote, 39, 1729-1735, doi:10.1109/36.942551, 2001.

Kerr, Y. H., Waldteufel, P., Wigneron, J.-P., Delwart, S., Cabot, F., Boutin, J., Escorihuela, M.-J., Font, J., Reul, N., Gruhier, C., Juglea, S. E., Drinkwater, M. R., Hahne, A., Martín- Neira, M., and Mecklenburg, S.: The SMOS Mission: New Tool for Monitoring Key Elements of the GlobalWater Cycle, P. IEEE, 98, 666-687, 2010.

Kerr, Y. H., Waldteufel, P., Richaume, P., Davenport, P., Ferrazzoli, P., and Wigneron, J.-P.: SMOS level 2 processor Soil Moisture Algorithm theoretical Basis Document (ATBD), Tech. Rep. SO-TN-ARR-L2PP-0037, V3.4, CBSA, UoR, TV and INRA, Toulouse, available at: http://www.cesbio.ups-tlse.fr/fr/ indexsmos.html (last access: 24 January 2011), 2011.

Kizito, F., Campbell, C. S., Campbell, G. S., Cobos, D., Teare, B., Carter, B., and Hopmans, J.: Frequency, electrical conductivity and temperature analysis of a low-cost capacitance soil moisture sensor, J. Hydrol., 352, 367-378, 2008.

Krauss, L., Hauck, C., and Kottmeier, C.: Spatio-temporal soil moisture variability in Southwest Germany observed with a new monitoring network within the COPS domain, Meteorolog. Z., 19, 523-537, 2010.

Leroux, D. J., Kerr, Y. H., Al Bitar, A., Gruhier, C., Bindlish, R., Jackson, T. J., Berthelot, B., and Portet, G.: Comparison between SMOS and other satellite and model forecast products, Remote Sens. Environ., in review, 2012.

Li, L., Gaiser, P. W., Gao, B.-C., Bevilacqua, R. M., Jackson, T. J., Njoku, E. G., Rüdiger, C., Calvet, J.-C., and Bindlish, R.: WindSat global soil moisture retrieval and validation, IEEE T. Geosci. Remote, 48, 2224-2241, 2010.

Martinez-Fernandez, J. and Ceballos, A.: Temporal stability of soil moisture in a large-field experiment in Spain, Soil Sci. Soc. Am. J., 67, 1647-1656, 2003.

Martinez-Fernandez, J. and Ceballos, A.: Mean soil moisture estimation using temporal stability analysis, J. Hydrol., 312, 28-38, 2005.

Masson, V., Champeaux, J., Chauvin, F., Meriguet, C., and Lacaze, R.: A global database of land surface parameters at $1 \mathrm{~km}$ resolution in meterological and climate models, J. Climate, 16, 12611282, 2003.

Merlin, O., Walker, J., Kalma, J., Kim, E., Hacker, J., Panciera, R., Young, R., Summerell, G., Hornbuckle, J., Hafeez, M., and Jackson, T.: The NAFE'06 data set: Towards soil moisture retrieval at intermediate resolution, Adv. Water Resour. Res., 31, 14441455,2008

Milthers, V: Beskrivelse til geologisk kort over Danmark, 1:100.000, Kortbladet Brande, Danmarks Geologiske Undersoegelse, 18, 162 pp., 1939.

Mironov, V., Dobson, M., Kaupp, V., Komarov, S., and Kleshchenko, V.: Generalized refractive mixing dielectric model for moist soils, IEEE T. Geosci. Remote, 42, 773-785, 2004.

Mohanty, B. P., Skaggs, T. H., and Famiglietti, J. S.: Analysis and mapping of field-scale soil moisture variability using highresolution, ground-based data during the Southern Great Plains 1997 (SGP97) Hydrology Experiment, Water Resour. Res., 36,
1023-1031, 2000.

Naeimi, V., Scipal, K., Bartalis, Z., Hasenauer, S., and Wagner, W.: An improved soil moisture retrieval algorithm for ERS and METOP scatterometer observations, IEEE T. Geosci. Remote, 47, 1999-2013, 2009.

Njoku, E. G., Jackson, T. J., Lakshmi, V., Chan, T. K., and Nghiem, S. V.: Soil moisture retrieval from AMSR-E, IEEE T. Geosci. Remote, 41, 215-229, 2003.

Owe, M., De Jeu, R. A., and Walker, J. P.: A methodology for surface soil moisture and vegetation optical depth retrieval using the microwave polarization difference index, IEEE T. Geosci. Remote, 39, 1643-1654, 2001.

Peplinski, N., Ulaby, F., and Dobson, M.: Dielectric properties of soils in the $0.3-1.3-\mathrm{GHz}$ range, IEEE T. Geosci. Remote, 33 , 803-807, 1995.

Reichle, R. and Koster, R.: Bias reduction in short records of satellite soil moisture, Geophys. Res. Lett., 31, L19501, doi:10.1029/2004GL020938, 2004.

Rosenbaum, U., Huisman, J., Weuthen, A., Vereecken, H., and Bogena, H.: Sensor-to-sensor variability of the ECH2O EC-5, TE and 5TE sensors in dielectric liquids, Vadose Zone J., 9, 181186,2010

Rüdiger, C., Walker, J. P., Kerr, Y. H., Mialon, A., Merlin, O., and Kim, E. J.: Validation of the Level 1c and Level 2 SMOS Products with airborne and ground-based observations, in: International Congress on Modelling and Simulation (MODSIM), Perth, Australia, 2011.

Schaefer, G. L., Cosh, M. H., and Jackson, T. J.: The USDA Natural Resources Conservation Service Soil Climate Analysis Network (SCAN), J. Atmos. Ocean. Tech., 24, 2073-2077, 2007.

Scharling, M.: Klimagrid Danmark Nedboer $10 \times 10 \mathrm{~km}$ (ver. 2), Technical Report 99-15, Danish Meteorological Institute, Copenhagen, p. 18, 1999 (in Danish).

Scheffer, F. and Schachtschabel, P.: Lehrbuch der Bodenkunde, Spektrum Akademischer Verlag $\mathrm{GmbH}$, Heidelberg, Berlin, 2002.

Schou, A.: Atlas over Danmark, 1:750.000, Det Kongelige Danske Geografisk Selskab med støtte af den Danske Stat, Carlsbergfondet og private virksomheder, H. Hagerup, C. A. Reitzels Forlag, København., 1949.

Smed, P.: Landskabskort over Danmark, 1:360.000, Geografforlaget, 5464 Brenderup, 1979.

Topp, G. C., Davis, J. L., and Annan, A. P.: Electromagnetic determination of soil water content: measurement in coaxial transmission lines, Water Resour. Res., 16, 574-582, 1980.

Vachaud, G., Passerat de Silans, A., Balabanis, P., and Vauclin, M.: Temporal stability of spatially measured soil water probability density function, Soil Sci. Soc. Am. J., 49, 822-828, 1985.

Vasquez, V. and Thomsen, A.: Calibration of a capacitance probe for groundwater recharge modeling based on soil moisture dynamics, in: 1st International Conference and Exploratory Workshop on Soil Architecture and Physio-chemical Functions (CESAR), Faculty of Agricultural Sciences, Aarhus University, Aarhus University Research Center Foulum, Denmark, 2010.

Wagner, W., Lemoine, G., and Rott, H.: A method for estimating soil moisture from ERS scatterometer and soil data, Remote Sens. Environ., 70, 191-207, 1999.

Walker, J. P., Willgoose, G. R., and Kalma, J. D.: The Nerrigundah data set: Soil moisture patterns, soil characteristics, and hydro- 
logical flux measurements, Water Resour. Res., 37, 2653-2658, 2001.

Western, A. W. and Bloeschl, G.: On the spatial scaling of soil moisture, J. Hydrol., 217, 203-224, 1999.

Western, A. W., Grayson, R. B., and Bloeschl, G.: Scaling of soil moisture: a hydrologic perspective, Annu. Rev. Earth Pl. Sci., 30, 149-180, 2002.
Wigneron, J.-P., Kerr, Y., Waldteufel, P., Saleh, K., Escorihuela, M.J., Richaume, P., Ferrazzoli, P., de Rosnay, P., Gurney, R., Calvet, J.-C., Grant, J., Guglielmetti, M., Hornbuckle, B., Mätzler, C., Pellarin, T., and Schwank, M.: L-band Microwave Emission of the Biosphere (L-MEB) Model: Description and calibration against experimental data sets over crop fields, Remote Sens. Environ., 107, 639-655, 2007. 